\title{
Potential Stemness of Frozen-Thawed Testicular Biopsies without Sperm in Infertile Men Included into the In Vitro Fertilization Programme
}

\author{
Martin Stimpfel, ${ }^{1}$ Thomas Skutella, ${ }^{2}$ Mikael Kubista, ${ }^{3,4}$ Elvira Malicev, ${ }^{5}$ \\ Sabine Conrad, ${ }^{6}$ and Irma Virant-Klun ${ }^{1}$ \\ ${ }^{1}$ Reproductive Unit, Department of Obstetrics and Gynaecology, University Medical Centre Ljubljana, 1000 Ljubljana, Slovenia \\ ${ }^{2}$ Institute for Anatomy and Cell Biology, School of Medicine, University of Heidelberg, 69120 Heidelberg, Germany \\ ${ }^{3}$ TATAA Biocenter, 41103 Göteborg, Sweden \\ ${ }^{4}$ Laboratory of Gene Expression, Institute of Biotechnology, Academy of Sciences of the Czech Republic, 14220 Prague, Czech Republic \\ ${ }^{5}$ Blood Transfusion Centre of Slovenia, 1000 Ljubljana, Slovenia \\ ${ }^{6}$ Institute for Anatomy, School of Medicine, University of Tübingen, 72074 Tübingen, Germany
}

Correspondence should be addressed to Irma Virant-Klun, irma.virant@kclj.si

Received 31 May 2011; Revised 28 October 2011; Accepted 30 October 2011

Academic Editor: Ji Wu

Copyright (C) 2012 Martin Stimpfel et al. This is an open access article distributed under the Creative Commons Attribution License, which permits unrestricted use, distribution, and reproduction in any medium, provided the original work is properly cited.

\begin{abstract}
We describe the potential stemness of a small amount of frozen-thawed testicular tissue without sperm obtained by biopsy from six patients undergoing assisted reproductive treatment. The patients were diagnosed with Sertoli Cell-Only Syndrome alone or combined with maturation arrest. Trying to provide the natural stem cell niche for cultured stem cells, all isolated cells from enzymatically degraded biopsies where cultured together in different culture media and the presence of putative mesenchymal and putative pluripotent ES-like stem cells was indicated using different methods. High throughput real-time quantitative PCR followed by multivariate analysis revealed the formation of distinct cell clusters reflecting high degree of similarity and some of these cell clusters expressed the genes characteristic for pluripotent stem cells. In the presence of the follicular fluid, prepared as serum, putative testicular stem cells showed a certain degree of plasticity, and spontaneously differentiated into adipose-like and neuronal-like cells. Additionally, using differentiation protocols putative testicular stem cells were differentiated into neuronaland pancreatic-like cells. This study shows that in assisted reproduction programmes, testicular tissue with no sperm might be an important source of stem cells, although it is discarded in daily medical practice; this requires further research.
\end{abstract}

\section{Introduction}

Stem cells derived from adult human tissues are of great scientific interest to provide potential individual cell-based therapy without ethical and immunological problems associated with human embryonic stem cells. Testicular tissue retrieved in the assisted reproduction programme might be an important source of stem cells. In infertile men with azoospermia (no sperm in the ejaculate), a diagnostic testicular biopsy is usually performed to find sperm and to cryopreserve it until use for in vitro fertilization. In a certain number of these patients, there is no sperm in the testicular tissue due to Sertoli Cell-Only Syndrome (SCOS) or maturation arrest (MA) of germ cells at different stages of development. In these patients, fresh or frozen-thawed testicular tissue is thrown away in daily medical practice, but could be used for the personalized cell therapy in the future. The majority of studies on testicular stem cells have been performed with the whole animal or human testicles or large biopsies [1-14], but in a clinical practice only small testicular biopsies of infertile men are available.

Most of the earlier studies concerning testicular stem cells were performed in the mouse model, mostly to study spermatogonial stem cells and their in vitro reprogramming [110]. This work was followed by studies on human testicular tissue [11-14], and the results have shown that germinal stem 
cells derived from the human and mouse testes have cellular and molecular characteristics comparable to pluripotent embryonic stem cells. Due to these properties, germinal stem cells seem to have a great potential for autologous cell-based therapies respecting their unstable imprinting patterns and potential teratoma formation [15]. Another possibility are multipotent mesenchymal stem cells with some advantages, such as immunomodulatory effects [16], keeping the functionality of organs, and regeneration of damaged tissues [1719]. Gonzalez et al. have isolated putative mesenchymal stem cells from adult human testes that they named gonadal stem cells [20]; these cells expressed markers characteristic of mesenchymal stem cells (CD105, CD73, CD90, CD166, and STRO-1), some markers characteristic of pluripotent stem cells (OCT4, NANOG, and SSEA-4), and were capable to differentiate into chondrogenic, adipogenic, and osteogenic lineages.

When talking about gonadal stem cell cultures and potential cell-based therapies, the role of the stem cell niche needs to be considered seriously since it may improve the conditions for cell growth, proliferation, and maintenance of natural properties [21]. It is known that stem cells isolated from the gonadal tissue (i.e., spermatogonial stem cells) change their properties when isolated from the testicular niche and that it is difficult to propagate and maintain them in vitro for a longer period [1]. Therefore, the aim of this study was to culture putative testicular stem cells with potentially pluripotent/multipotent character in the presence of other testicular cells, including Sertoli cells, which are known to have an important role in the regulation of spermatogonial fate and support of other testicular cells [22]. Moreover, we were trying to evaluate the stemness of small testicular biopsies of infertile men with no sperm. Putative testicular stem cells were differentiated into different types of cells by differentiation protocols and by heterologous follicular fluid retrieved from patients undergoing in vitro fertilization and rich in different substances important for germ cell growth, differentiation, and maturation, added to the conventional culture media.

\section{Materials and Methods}

2.1. Testicular Tissue Retrieval. Into this study six infertile men from the assisted reproduction programme were included. They were aged from 21 to 41 years (mean age: 34.3 years). In each patient, an approximately $5 \mathrm{~mm}^{3}$ volume of testicular tissue was retrieved at diagnostic biopsy to obtain sperm before the potential in vitro fertilization procedure. In all patients the observation under an inverted microscope revealed no sperm in the tissue. A part of the tissue was sent to the Unit of Pathology, where the hematoxylin-eosin (HE) staining of testicular tissue sections was performed and observed by the very experienced pathologist. HE staining revealed SCOS in two patients and SCOS combined with MA in remaining patients. The testicular tissue was used for research purposes after the patient's written consent according to the research approval of the National Medical Ethical Committee (Ministry of Health, Republic of Slovenia).
2.2. Testicular Tissue Cryopreservation. Testicular tissue retrieved at the diagnostic biopsy was cut into smaller pieces with a sterile surgical blade. It was diluted in a freezing medium: Flushing medium (Origio, Denmark) containing $20 \%$ of cryoprotectant glycerol (1v/v of tissue versus $2 \mathrm{v} / \mathrm{v}$ of freezing solution) in two $2 \mathrm{~mL}$ vials. The tissue was cooled in a liquid nitrogen vapour in a L'Air Liquide machine (France) by the slow-freezing programme: from $20^{\circ} \mathrm{C}$ to $-6^{\circ} \mathrm{C}$ at $5^{\circ} \mathrm{C} /$ minute, from $-6^{\circ} \mathrm{C}$ to $-30^{\circ} \mathrm{C}$ at $10^{\circ} \mathrm{C} /$ minute, and from $-30^{\circ} \mathrm{C}$ to $-140^{\circ} \mathrm{C}$ at $20^{\circ} \mathrm{C} /$ minute. After cooling, vials with the testicular tissue were transferred into the liquid nitrogen at $-196^{\circ} \mathrm{C}$ and stored until use.

2.3. Follicular Fluid Retrieval. In the in vitro fertilization programme, the follicular fluid was retrieved at the oocyte aspiration and after a written consent was donated by two young patients with a normal ovarian reserve and normal response to the hormonal ovarian stimulation. Previous testing on HIV and hepatitis viruses revealed that they were healthy. Follicular fluid was used immediately after the removal of the oocytes so as not to coagulate. To prepare the follicular fluid, it was centrifugated for 10 minutes at 2,500 rpm. The supernatant was filtered through a sterile Sartorius Minisart $0.45 \mu \mathrm{m}$ filter to remove all possible cells (i.e., granulosa cells, theca cells, blood cells, and cells from the immunological system). The filtered supernatant was heat inactivated at $56^{\circ} \mathrm{C}$ for 45 minutes. Then it was aliquoted and stored at $-20^{\circ} \mathrm{C}$ until use.

2.4. Testicular Tissue Thawing, Isolation, and Culture of Testicular Cells. Two vials of frozen testicular tissue of each patient were thawed in a water bath $\left(37^{\circ} \mathrm{C}\right)$, and the content of the vials was transferred into a warm Dulbecco's Modified Eagle's Medium (DMEM)/Nutrient Mixture F12 Ham with L-glutamine and $15 \mathrm{mM}$ HEPES (Sigma, cat.no. D8900). This medium was supplemented with $3.7 \mathrm{~g} / \mathrm{L} \mathrm{NaHCO}_{3}, 1 \%$ penicillin/streptomycin (Sigma), and the $\mathrm{pH}$ was adjusted to 7.4 with $1 \mathrm{M} \mathrm{NaOH}$. The whole frozen-thawed testicular tissue was enzymatically degraded in two steps according to the modified protocol of Kanatsu-Shinohara et al. [1]. We did not isolate any special type of testicular cells but handled the whole population of testicular cells to enable the testicular niche to potential stem cells, if present. After enzymatic degradation at least 100.000 testicular cells were retrieved, as counted in a Neubauer counting chamber. Approximately $60 \%$ of cells survived the freeze-thawing procedures, as revealed by Trypan Blue staining. Then testicular tissue was centrifuged for 8 minutes at $1,500 \mathrm{rpm}$, and after centrifugation the supernatant was removed. The pellet was resuspended in collagenase type XI $(0.5 \mathrm{mg} / \mathrm{mL})$, incubated for 10 minutes at $37^{\circ} \mathrm{C}$, and centrifuged for 8 minutes at $1,500 \mathrm{rpm}$ again. After centrifugation, the supernatant was removed and the pellet resuspended in an enzyme mixture of collagenase type XI $(0.5 \mathrm{mg} / \mathrm{mL}$ ) and hyaluronidase (SynVitro Hydase, Origio). After 10 minutes of incubation at $37^{\circ} \mathrm{C}, 20 \%$ fetal bovine serum (FBS) was added to inactivate enzymes, and the suspension of cells was vigorously stirred and left for 5 minutes to separate the bigger pieces of tissue from 
the suspension of cells by gravity. The supernatant was then collected and centrifuged for 8 minutes at 1,500 rpm. This gravity separation was done in first three isolations of testicular cells. In further isolations the suspension of cells was passed through a $70 \mu \mathrm{m}$ cell strainer (BD Falcon) and centrifuged for 8 minutes at $1,500 \mathrm{rpm}$. After centrifugation the supernatant was removed, and the pellets were resuspended in culture media.

\section{The Plasticity of Cell Cultures Was Tested on Two Different Ways}

3.1. By Culturing of Isolated Cells in Conventional Media with or without Follicular Fluid. Cells were cultured in the following culture media: (1) DMEM/F12 with 20\% FBS, (2) DMEM/F12 with 20\% follicular fluid (FF), and (3) medium, which is usually used to culture human embryonic stem cells—hESC medium: DMEM/F12, 20\% KnockOut Serum Replacement (Gibco), $1 \mathrm{mM}$ L-glutamine (PAA), 1\% nonessential amino acids (PAA), $0.1 \mathrm{mM}$ 2-mercaptoethanol (Invitrogen), $13 \mathrm{mM}$ HEPES, and $4 \mathrm{ng} / \mathrm{mL}$ human basic FGF (Sigma). For each biopsy one gelatin-coated 4-well culture dish (Nunc) was used to establish the primary cell culture. Subculturing of cells was performed when necessary with collagenase type IV (Sigma) or with trypsin (Sigma). The cells were cultured in a $\mathrm{CO}_{2}$ incubator at $37^{\circ} \mathrm{C}$ and $6 \% \mathrm{CO}_{2}$ in air and daily monitored at the heat-staged inverted microscope (Nikon, Japan) under 40x, 100x, and 200x magnifications (Hoffman illumination). All cell cultures were performed at the University Medical Centre Ljubljana.

3.2. Or By In Vitro Differentiation of Cell Cultures. Neural differentiation was performed as described previously [23], with some modifications. Briefly, the cells from approximately 10-day-old cultures were cultured on matrigel in DMEM/ F12 culture medium supplemented with 1\% HSA-human serum albumin, $80 \mathrm{ng} / \mathrm{mL}$ human basic FGF, $30 \mu \mathrm{M}$ forskolin, $1 \%$ nonessential amino acids, $0.1 \mathrm{mM} 2$-mercaptoethanol, and $1 \%$ of Insulin-Transferrin-Selenium (ITS). The cells were daily monitored, and after first morphological changes (approximately 2 days) they were stained using immunocytochemistry.

To initiate pancreatic differentiation cells from approximately 10-day-old cultures were cultured for 7 days on gelatine in pancreatic proliferation medium (DMEM/F12 supplemented with $1 \%$ of $\mathrm{N} 2,2 \%$ of $\mathrm{B} 27,1 \%$ of penicillin/ streptomycin, and $25 \mathrm{ng} / \mathrm{mL} \mathrm{bFGF)} \mathrm{and} \mathrm{then} \mathrm{for} 15$ days in pancreatic differentiation medium (DMEM/F12 supplemented with $1 \%$ of $\mathrm{N} 2,2 \%$ of B27, $1 \%$ of penicillin/streptomycin and $10 \mathrm{mM}$ nicotinamide) [24-26].

\section{Cell Analyses}

4.1. Alkaline Phosphatase Staining. An alkaline phosphatase detection kit (Millipore) was used for alkaline phosphatase (AP) staining for the presence of pluripotent and mesenchymal stem cells. Briefly, the cells were fixed in $4 \%$ paraformaldehyde for 3 minutes, permeabilized with $0.2 \%$ Tween- 20 for 10 minutes and incubated for 30 minutes in a working solution of reagents, which consisted of Fast Red Violet, Naphtol AS-BI phosphate solution and water in a $2: 1: 1$ ratio. The culture was observed under an inverted microscope (Hoffman illumination) to confirm AP activity. The cells or cell colonies expressing AP activity were stained from pink to a red colour.

4.2. Oil Red O Staining. Oil Red O staining was used to confirm the adipogenic differentiation of cultured cells. The cells were fixed in $4 \%$ paraformaldehyde for 30 minutes and incubated for 10 minutes in an Oil Red $\mathrm{O}$ working solution. After staining, the cells were washed 2 times with PBS and observed under an inverted microscope (Hoffman illumination) to detect the red staining of the lipid droplets.

4.3. Flow Cytometry. The cells were analyzed by using FITC(fluorescein isothiocyanate-) conjugated antibodies against CD105 (EuroClone) and PE- (phycoerythrin-) conjugated antibodies against SSEA-4 (BD Pharmingen). Mouse IgG3 conjugated with PE (BD Pharmingen) and mouse IgG1 conjugated with FITC antibodies (BD Pharmingen) were used as isotype controls. The analyzed testicular cell culture was previously cultured in a DMEM/F12 culture medium with $20 \%$ of follicular fluid, prepared as serum, on a gelatine-coated plate for 84 days ( 8 passages) before analysis. The whole cell culture was collected, including the cell clusters, which were treated with trypsin to achieve single-cell suspension. The sample was analyzed by using FACSCalibur (BD) and the data by using BD CellQuest Pro Software. A proportion of stained cells was monitored under a fluorescent microscope to evaluate the morphology of the CD105- and SSEA-4-positive cells.

4.4. Dithizone Staining. Dithizone staining of cell cultures was performed as described previously [27]. Briefly, the stock solution of dithizone was prepared by dissolving $10 \mathrm{mg}$ of dithizone in $1 \mathrm{~mL}$ of dimethyl sulfoxide (DMSO). Then $10 \mu \mathrm{l}$ of stock solution was added to $1 \mathrm{~mL}$ of DMEM/F12, filtered through a $0,4 \mu \mathrm{m}$ filter, and cells were incubated in this working solution for 15 minutes at $37^{\circ} \mathrm{C}$. After incubation cells were washed 4 times with PBS and observed under an inverted microscope.

4.4.1. Immunocytochemistry. Cells were fixed in $4 \%$ paraformaldehyde and permeabilized with $0.2 \%$ Triton and then incubated with $3 \% \mathrm{H}_{2} \mathrm{O}_{2}$ for 10 minutes to block the endogenous peroxidase activity and for 20 minutes with $10 \%$ FBS to block the nonspecific binding sites. Then the cells were incubated for 1 hour at room temperature with following primary antibodies: mouse antinestin monoclonal antibodies (clone 10C2, 1:200, Millipore), rabbit anti-S100 polyclonal antibodies (1:500, Dako), rabbit anti-insulin (H-86) polyclonal antibodies $(1: 200$, Santa Cruz Biotechnology), mouse anti-C-peptide monoclonal antibodies (1:100, BioVendor), rabbit anti-NSE polyclonal antibodies $(1: 70, \mathrm{Abcam})$, and mouse anti-NeuN monoclonal antibodies $(1: 200$, Millipore). After washing with PBS, the cells were incubated with 


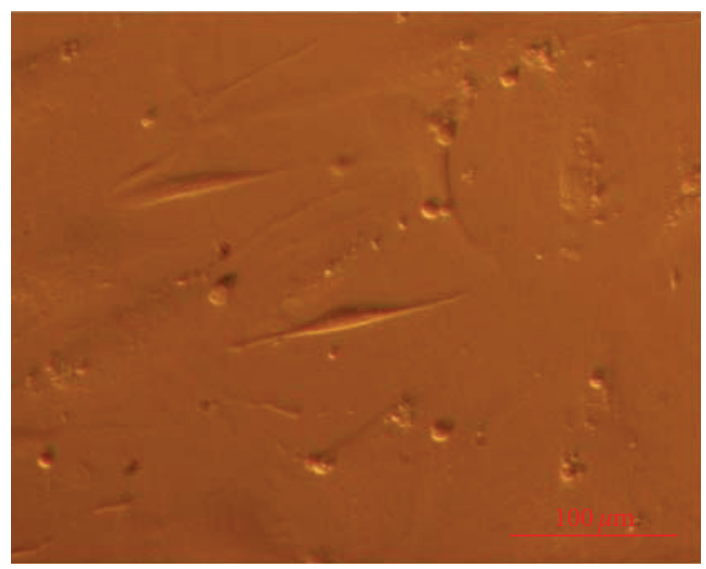

(a)

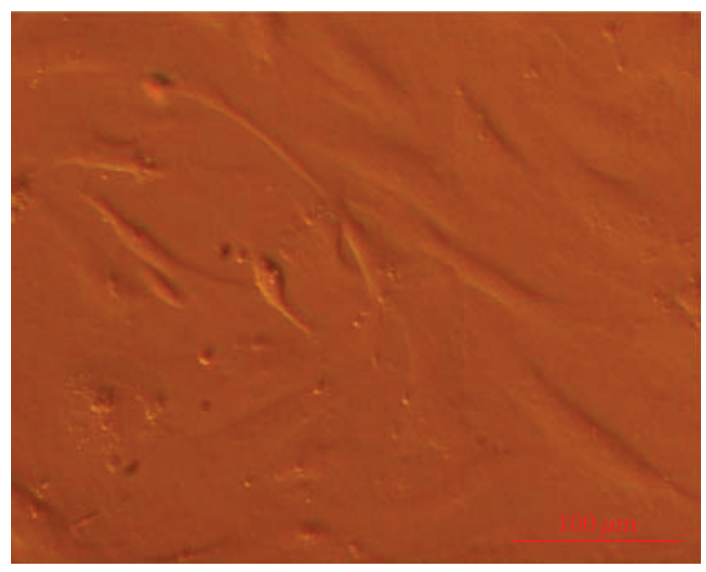

(b)

Figure 1: Cell culture grown in a DMEM/F12 medium supplemented with FBS. (a) The second passage of cell culture on day 76 . (inverted microscope, Hoffman). Scale Bar: $100 \mu \mathrm{m}$.

biotinylated secondary antibodies (polyclonal rabbit antimouse Immunoglobulins $(1: 400)$ or polyclonal goat antirabbit Immunoglobulins (1:600), both DakoCytomation) for 30 minutes and then with an $\mathrm{ABC}$ reagent (Vectastain ABC Kit-Standard) for 30 minutes. Finally, the cells were incubated in a DAB substrate (Sigma) until the brown staining appeared (usually about 5 minutes), washed with PBS and observed under an inverted microscope (Hoffman illumination) to detect positive brown-stained cells or cell colonies. For a negative control, the primary antibodies were omitted from the procedure and replaced with $1 \%$ FBS.

4.4.2. Gene Expression Analyses. Gene expression analyses of putative stem cells cultured in different media were performed using the Biomark Real-Time quantitative PCR (qPCR) system (Fluidigm). In all samples, expressions of 19 genes: OCT4A, OCT4B, LIN28, GDF3, NANOG, MYC, KLF4, SOX-2, UTF1, TDGF1, DNMT3B, LIN28B, TERT, CD9, NANOS, CDH1, STAT3, REX01, DNMT1 mostly related to pluripotency, and of the housekeeping gene GAPDH, which was used for normalization, were analyzed. The inventoried TaqMan assays (20x, Applied Biosystem) were pooled to a

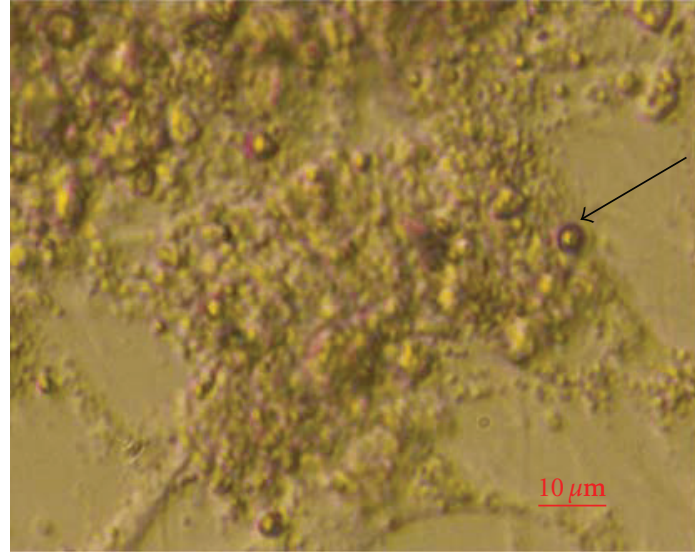

(a)

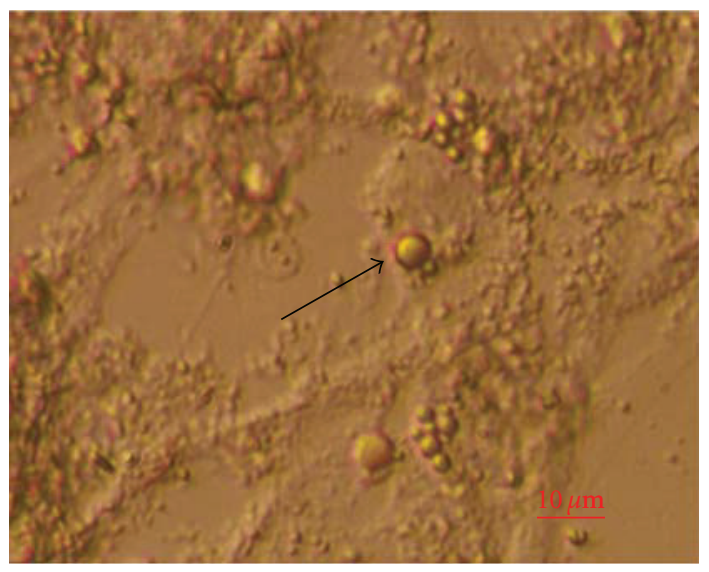

(b)

FIGURE 2: Presence of small round cells (arrow) grown in an ESC medium (day 6). (inverted microscope, Hoffman). Scale Bar: $10 \mu \mathrm{m}$.

final concentration of $0.2 \mathrm{x}$ for each of the 20 assays. Testicular cell clusters, human embryonic stem cells (hESC; positive control), and human fibroblast samples (F161; negative control) were harvested directly into $9 \mu \mathrm{L}$ RT-PreAmp Master Mix (5.0 $\mu \mathrm{L}$ CellsDirect 2x Reaction Mix (Invitrogen); $2.5 \mu \mathrm{L}$ $0.2 \mathrm{x}$ assay pool; $0.2 \mu \mathrm{L}$ RT/Taq Superscript III [Invitrogen]; $1.3 \mu \mathrm{L}$ TE buffer). The harvested cells were immediately frozen and stored at $-80^{\circ} \mathrm{C}$. Cell lysis and sequence-specific reverse transcription were performed at $50^{\circ} \mathrm{C}$ for $15 \mathrm{~min}$. The reverse transcriptase was inactivated by heating to $95^{\circ} \mathrm{C}$ for $2 \mathrm{~min}$. Subsequently, in the same tube, cDNA went through limited sequence-specific amplification by denaturing at $95^{\circ} \mathrm{C}$ for $15 \mathrm{~s}$, and annealing and amplification at $60^{\circ} \mathrm{C}$ for 4 min for 14 cycles. These preamplified products were diluted 5-fold prior to analysis with Universal PCR Master Mix and inventoried TaqMan gene expression assays (ABI) in 96.96 Dynamic Arrays on a BioMark System. Each sample was analyzed in two technical replicates. Ct values were obtained from the BioMark System and were transferred to the GenEx software (MultiD). Missing data in the Biomark system were given a Ct of 999. These were removed in GenEx. Also Ct's larger than 30 were removed, since samples with such high Ct's in the Biomark $96 \times 96$ microfluidic card were expected 


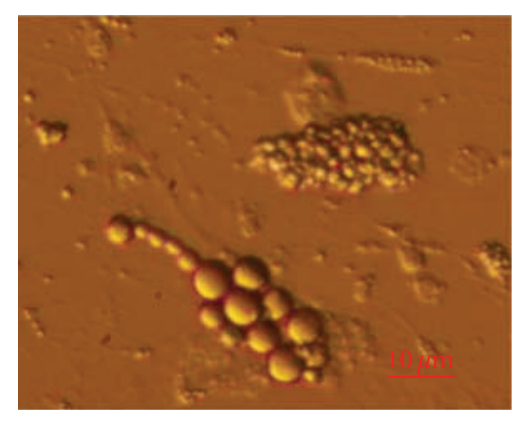

(a)

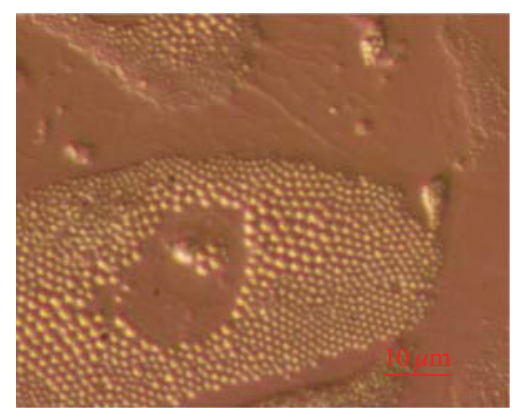

(c)

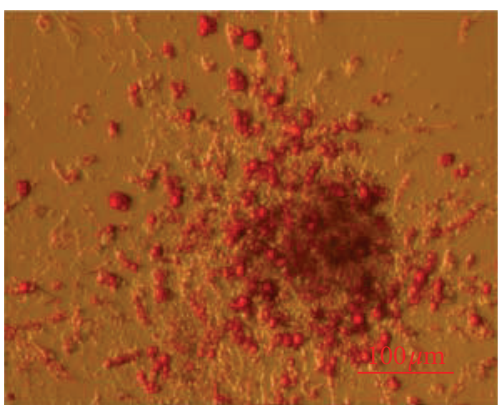

(e)

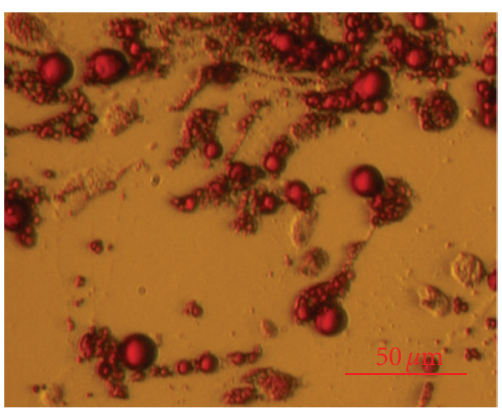

(g)

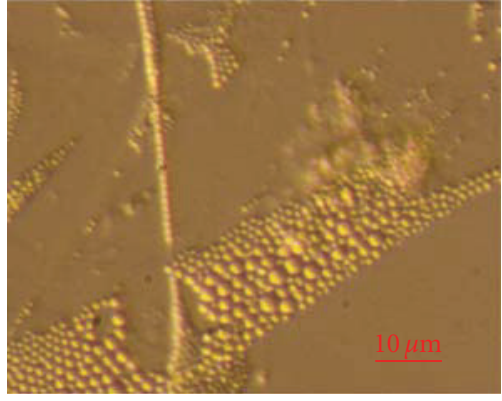

(b)

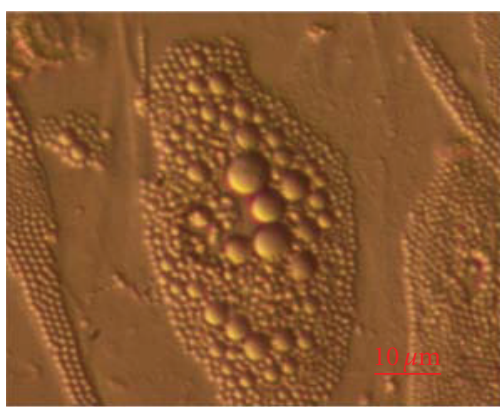

(d)

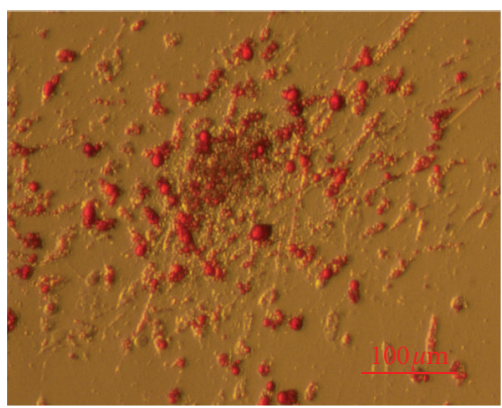

(f)

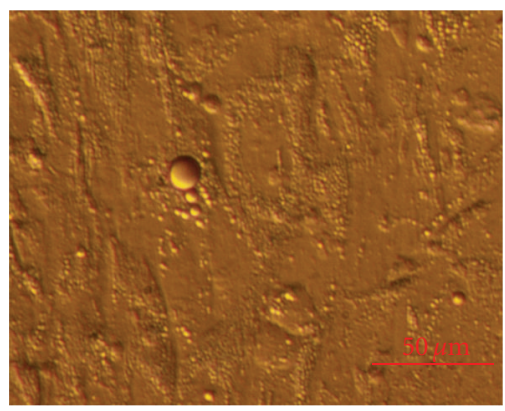

$(\mathrm{h})$

FIGURE 3: Accumulation of lipid droplets in cells cultured in an ESC medium with added follicular fluid. (a, b, c, d) Cell culture before staining with Oil Red O. (e, f, g) Cell culture stained with Oil Red O (passage 3, day 68). (h) Negative control. (inverted microscope, Hoffman). Scale Bar: (a-d) $10 \mu \mathrm{m}$. (e, f) $100 \mu \mathrm{m}$. (g, h) $50 \mu \mathrm{m}$.

to be negative, and these readings were unreliable. Technical repeats were then averaged. Missing data were then replaced by the highest $\mathrm{Cq}+1$ for each gene. This corresponded to assigning a concentration to these samples that was half of the lowest concentration measured and was motivated by sampling ambiguity. There was also a need to handle missing data for downstream classification with multivariate tools. Linear quantities were calculated relative to the sample having lowest expression, and data were converted to $\log _{2}$ scale. 


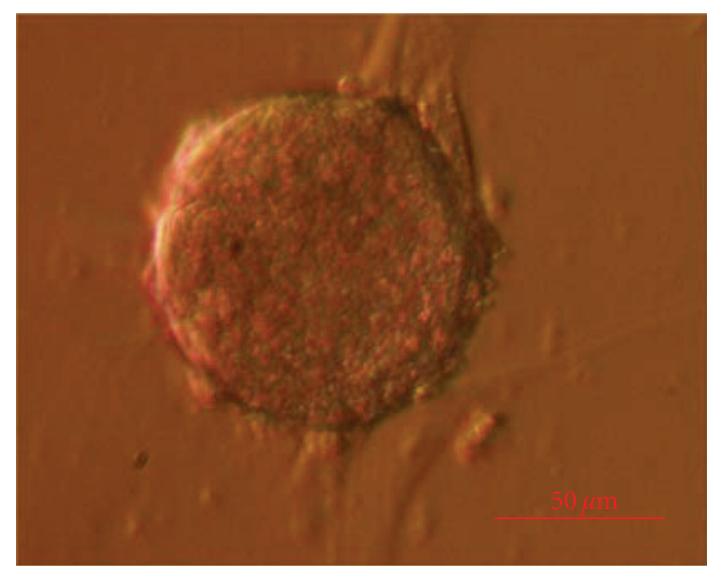

(a)

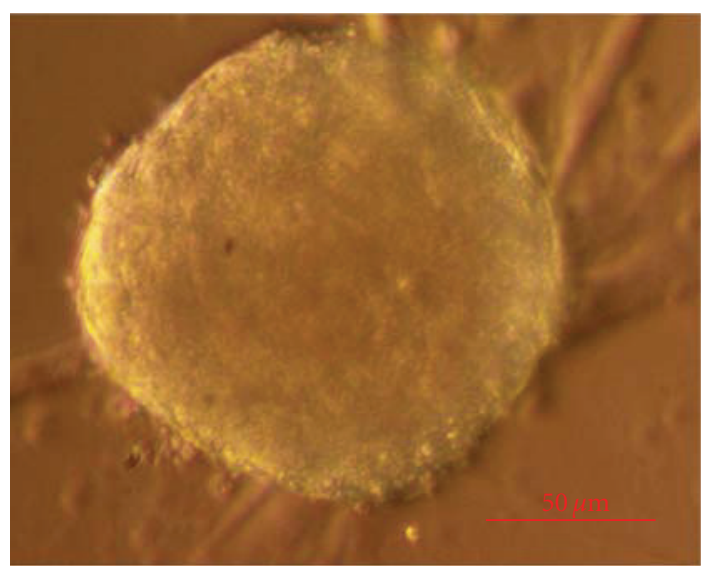

(b)

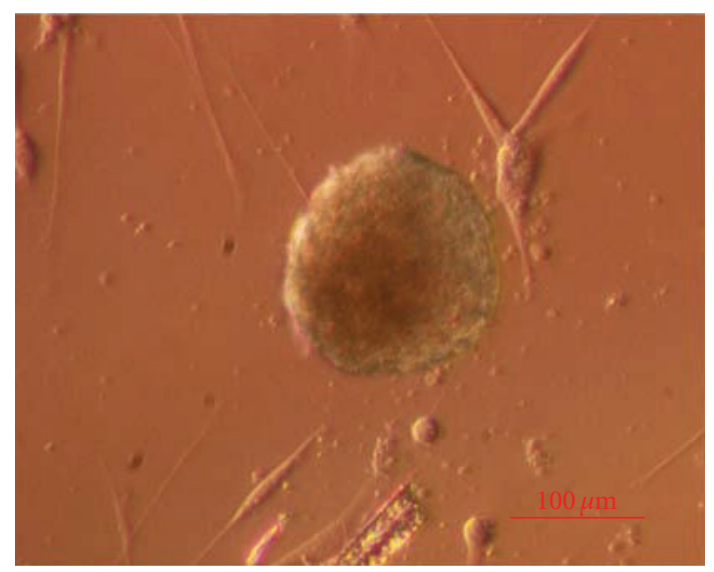

(c)

Figure 4: Cell colonies grown in a DMEM/F12 culture medium with added follicular fluid (passage 3, day 33) on native testicular fibroblasts. (inverted microscope, Hoffman). Scale Bar: (a, b) $50 \mu \mathrm{m}$ and for (c) is $100 \mu \mathrm{m}$.

The data were now prepared for multivariate analysis to classify the samples based on the combined expression of all the genes. Heatmap, hierarchical clustering (Ward's Algorithm, Euclidean Distance Measure) and principal component analysis (PCA) were performed. In addition, descriptive statistics was calculated individually for the genes using $0.95 \%$ confidence level and groups were compared using 1-way ANOVA and unpaired 2-tailed $t$-Test. Statistical significance was set at $P<0.00269$ (Bonferroni correction) to account for false positives due to multiple testing. The groups of samples compared were: putative testicular stem cells (TSC), human embryonic stem cells (hESC), and human fibroblasts (F161).

\section{Results and Discussion}

Testicular cell culture, forming cell colonies and persisting in a condition in vitro, was successfully established from testicular biopsies of 5 from 6 infertile men.

\subsection{Plasticity of Cell Cultures in Conventional Culture Media} with or without Added Follicular Fluid. This is the first report on the use of heterologous follicular fluid retrieved in the in vitro fertilization programme as a media supplement to culture cells isolated from the frozen-thawed testicular tissue. In the in vitro fertilization programme, follicular fluid retrieved in infertile women after hormonal ovarian stimulation is normally discarded after oocyte removal and could be used as an interesting supplement to culture media, while it contains several components important for cell growth, differentiation, and maturation, such as estrogens, progesterone, FSH, and androgens [28], proteins [29], amino acids [30], a high concentration of lipids-free cholesterol and meiosis-activating sterol (FF-MAS) [30,31], growth factors [32], stem cell factor (SCF) [33], and other substances important for cell growth, differentiation, and maturation.

At the beginning of this experiment, three different culture media were used to establish a primary cell cultures: DMEM/F12 with 20\% FBS, DMEM/F12 with 20\% follicular fluid (FF), and a culture medium which is usually used to culture human embryonic stem cells (hESC medium). The primary cell cultures were successfully established in all three culture conditions. After 2 weeks of culture, there were distinguishable morphological differences between them.

\subsubsection{Culture 1: DMEM/F12 Culture Medium with Added Fetal Bovine Serum (FBS). The cell cultures consisted of}




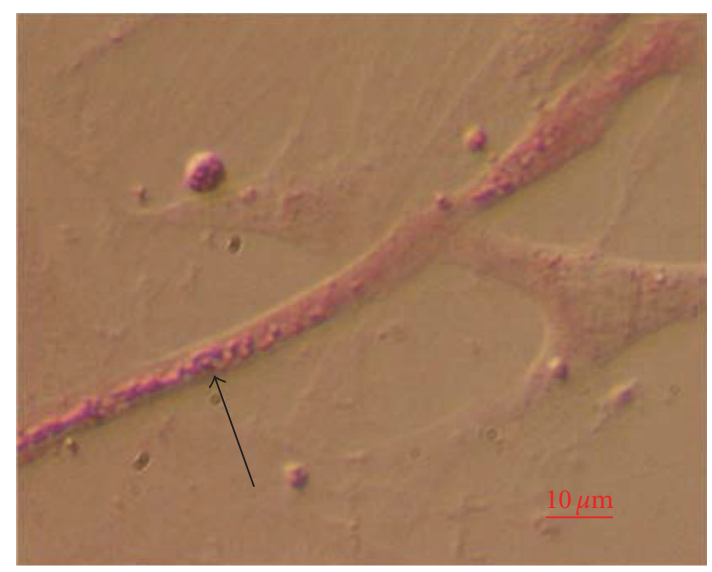

(a)

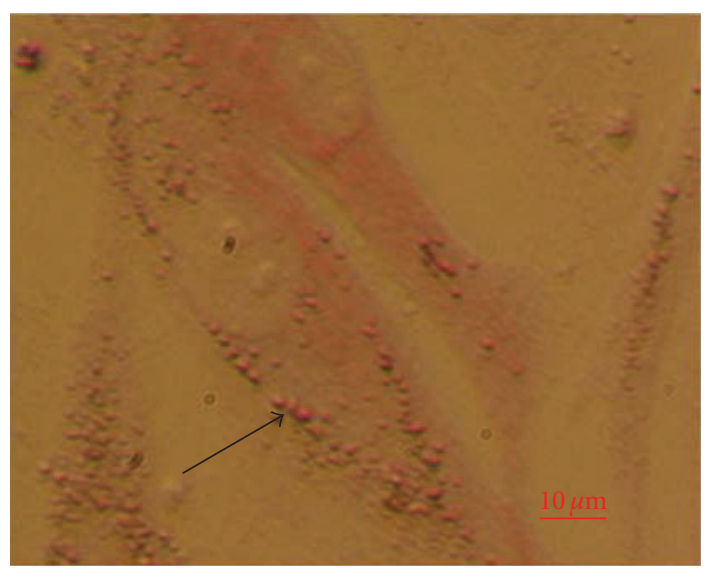

(b)

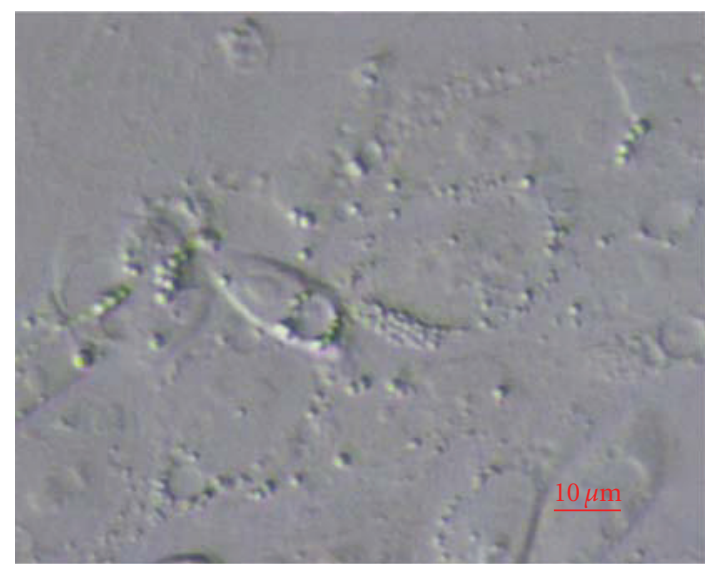

(c)

Figure 5: Alkaline phosphatase staining of cells grown in a DMEM/F12 culture medium with added follicular fluid (passage 3, day 44). (a, b) Some attached cells with a phenotype comparable to mesenchymal stem cells and small round cells with diameters of up to $5 \mu \mathrm{m}$ (arrow), weakly positive for alkaline phosphatase activity. (c) Negative control. (inverted microscope, Hoffman). Scale Bar: $10 \mu \mathrm{m}$.

adherent fibroblasts or fibroblast-like cells. During passages, these cell cultures showed very little change. After passages up to 114 days, the cell cultures were morphologically similar to what they were at the beginning (Figure 1).

\subsubsection{Culture 2: Human Embryonic Stem Cell (hESC) Culture} Medium with or without Added Follicular Fluid (FF). These cell cultures morphologically looked different from the cell cultures grown in the DMEM/F12 medium with added FBS, and they were more similar to the cell cultures grown in the DMEM/F12 medium with added follicular fluid. Structures which morphologically resembled embryoid bodies were observed. They usually developed on the native testicular fibroblasts. At this culture condition, a proliferation of small, yellow-coloured round cells with different diameters of up to $5 \mu \mathrm{m}$ was found (Figure 2). These cells appeared as single cells, small clusters of cells, or cells attached to other types of cells (i.e., fibroblasts). A similar type of Oct4A- positive cells has been previously identified in histological sections and cell cultures of adult human testes by Bhartiya et al. [38] and adult human ovaries [39]. Very comparable small cells were also found in other adult human tissues and organs as reported by Ratajczak and his group in more publications [3638]. They named the cells they found as very small embryonic-like (VSEL) stem cells.

The cell cultures were passaged and were transferred to matrigel-coated plates. Around day 20, 5\% follicular fluid was added to the culture medium. Seven days later, the cell cultures were passaged into the hESC medium without the follicular fluid. Around day 40, small lipid droplets were observed in the cell cultures (Figures 3(a)-3(d)), and 3 weeks later cell cultures were stained with Oil Red O to confirm lipids. A proportion of cells and cell colonies stained positively for the presence of lipids (Figures 3(e)-3(h)). There were also cells which did not accumulate lipid droplets. This phenomenon was not observed, when cells were cultured in the same way on the gelatine instead of matrigel.

\subsubsection{Culture 3: DMEM/F12 Culture Medium with an Added} Follicular Fluid (FF). The cell cultures were morphologically similar to the cell cultures grown in the hESC medium, and some round structures morphologically resembling embryoid bodies developed (Figure 4). These cell cultures were 


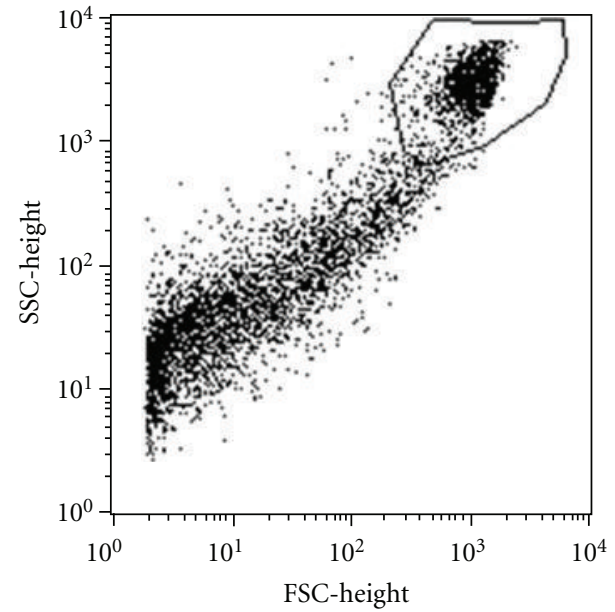

(a)

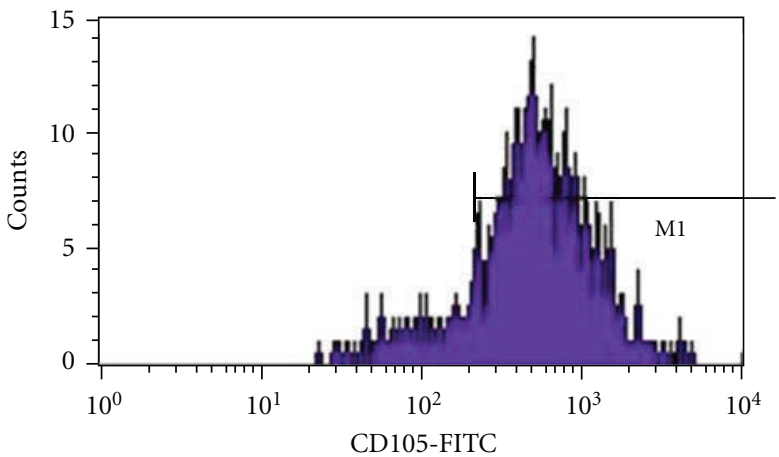

(b)

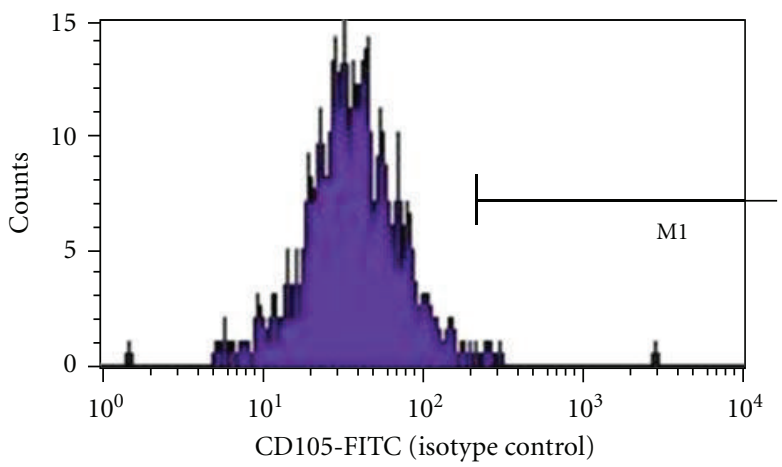

(c)

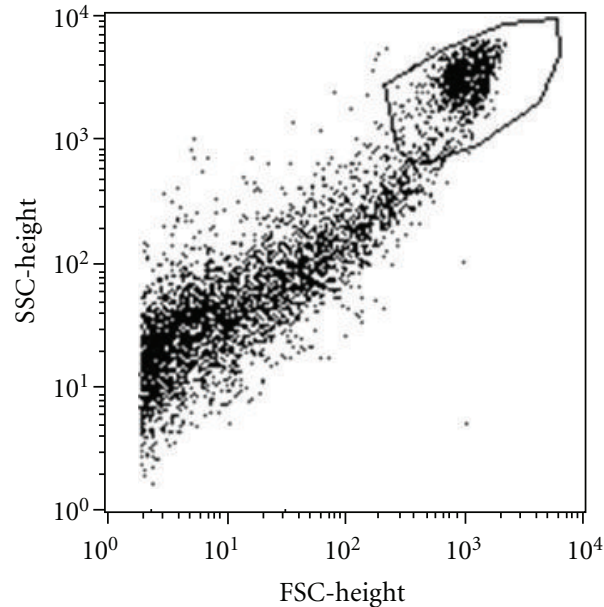

(d)

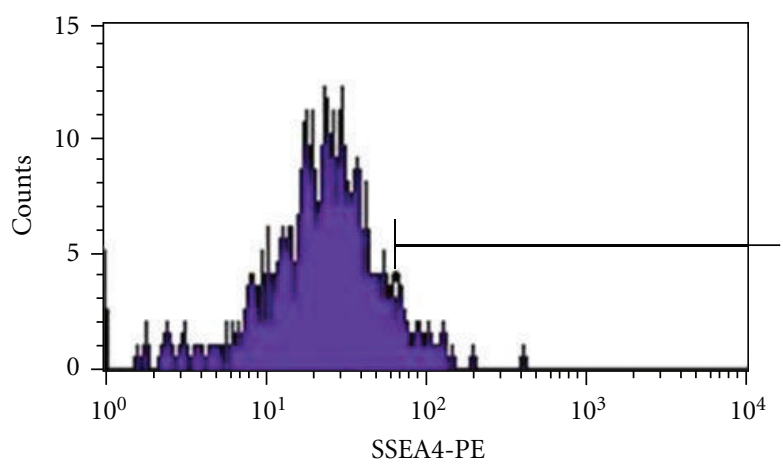

(e)

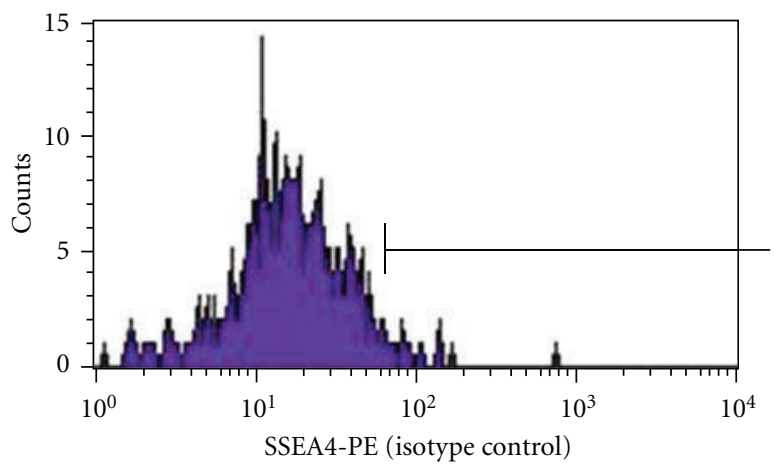

(f)

FIGURE 6: Flow cytometry analysis of cells grown in a DMEM/F-12 culture medium with added follicular fluid. (a, b) A subpopulation of cells expressing a mesenchymal stem cell marker-CD105-FITC. (c) Isotype control. (d, e) A subpopulation of cells expressing a stem cell marker-SSEA-4-PE. (f) Isotype control.

passaged, and at passage 2 they were transferred to the gelatine- and matrigel-coated plates. There were no cells accumulating lipid droplets. The cells formed clusters, and at passage 3 the cell cultures were stained for the presence of alkaline phosphatase activity. Some single cells with mesenchymal stem cell-like morphology attached to the dish bottom and some small round cells with diameters up to $5 \mu \mathrm{m}$ attached to other types of cells were weakly positive for alkaline phosphatase activity (Figure 5) thus indicating the possible presence of mesenchymal or pluripotent stem cells in the cell culture. This assumption was also supported by the flow cytometry analyses, which confirmed the presence of a subpopulation of CD105-positive cells (87.0\%) (Figures $6(\mathrm{a})-6(\mathrm{c}))$ and a small proportion of SSEA-4-positive cells (2.0\%) (Figures 6(d)-6(f)) around 80 days of cell culture. The relatively low proportion of SSEA-4-positive cells may reflect the fact that many cells were attached to other types of cells, and the whole cell culture consisted of different types of cells, including fibroblasts. CD105-positive cells were round and with diameters of approximately $10 \mu \mathrm{m}$, whereas SSEA-4-positive cells were smaller-with diameters of up to $5 \mu \mathrm{m}$ but with a quite strong expression of SSEA-4 surface 


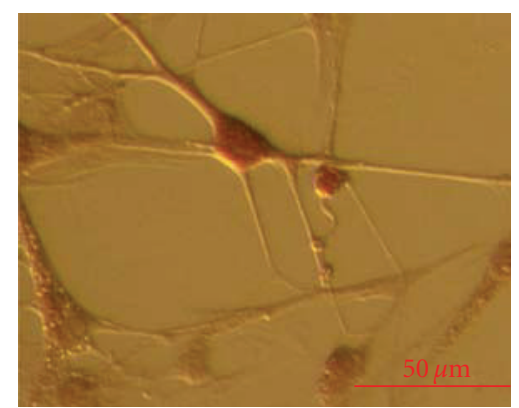

(a)

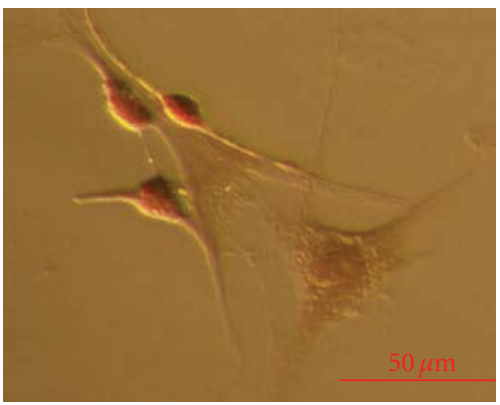

(c)

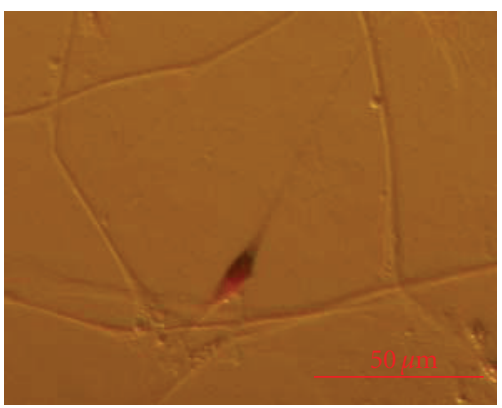

(e)

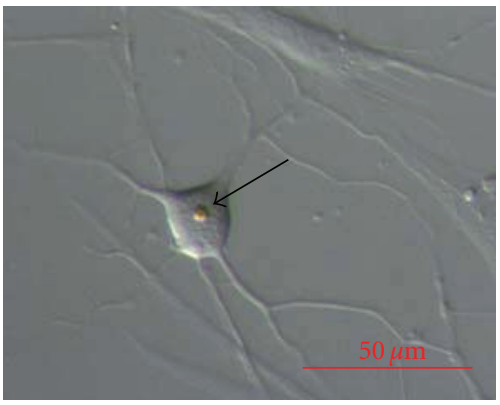

$(\mathrm{g})$

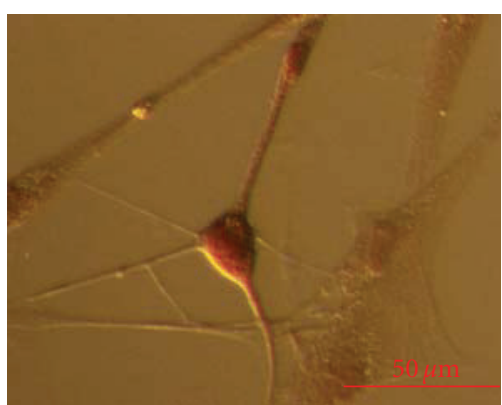

(b)

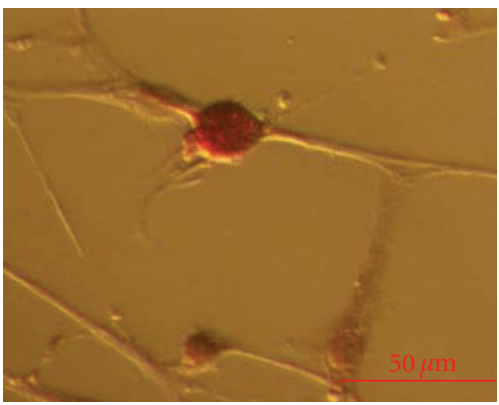

(d)

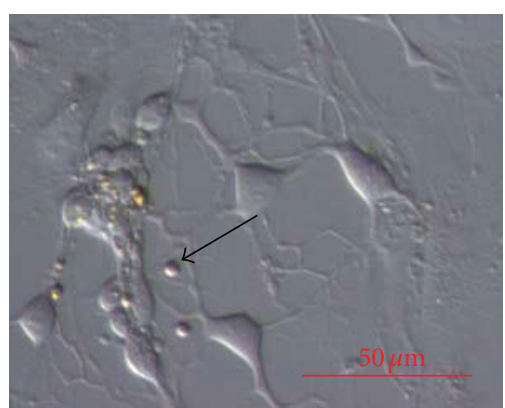

(f)

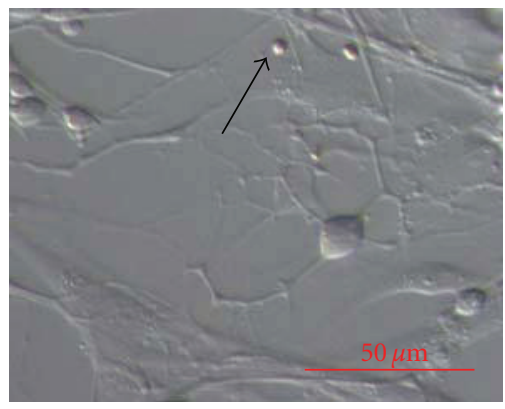

(h)

Figure 7: Differentiation of neuronal-like cells. (a-d) S100-positive cells. (e) Single nestin-positive elongated cell (arrow). (f-h) Negative controls with present small round cells (arrows) with diameters of up to $5 \mu \mathrm{m}$. (inverted microscope, Hoffman). Scale Bar: $50 \mu \mathrm{m}$.

antigen and nuclear staining by DAPI, as revealed by fluorescent microscopy. Besides pluripotent germinal stem cells derived from otherwise unipotent spermatogonia by reprogramming, as published before [11-14], there might be still another (maybe native) source of pluripotency in the adult human testes.

Around day 90, some of the cells spontaneously began to differentiate into neuronal-like cells. The cell cultures were stained for the expression of nestin, and a few elongated cells were indeed positive for nestin (Figure 7(e)). We supposed that these cells differentiated in vitro, because they were not present in the primary cell culture and earlier passages of this cell culture.

5.2. Plasticity of Cell Cultures Tested by Different Differentiation Protocols. When cell cultures were cultured in the media 


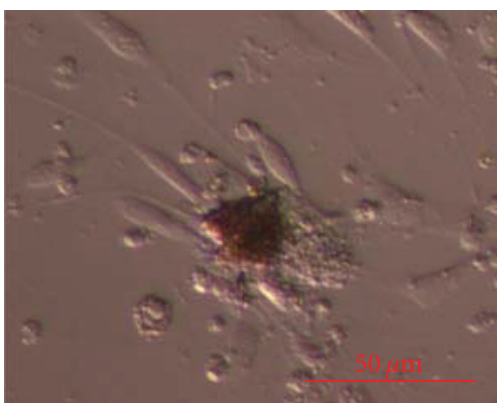

(a)

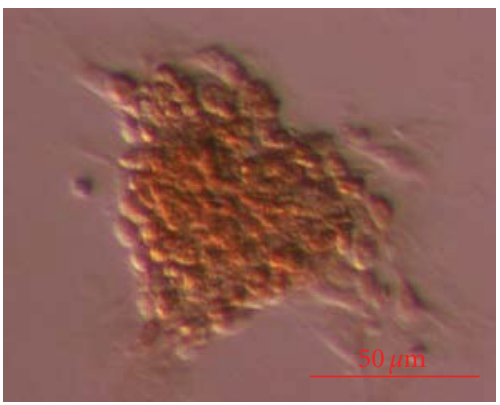

(c)

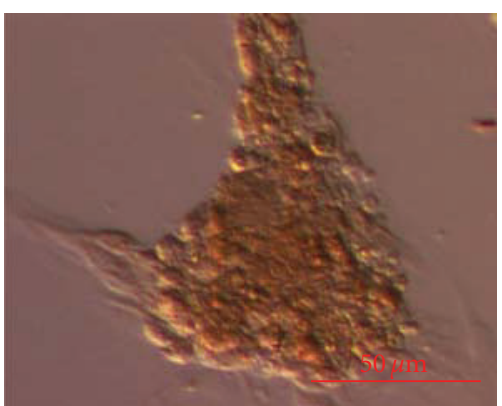

(e)

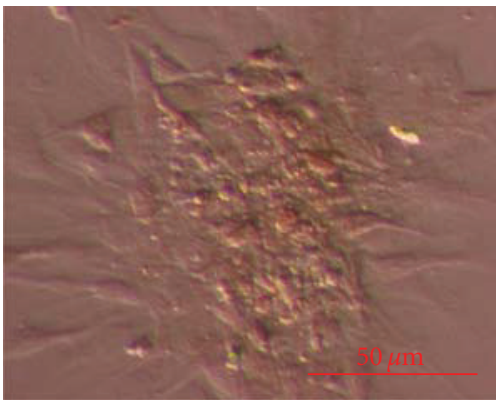

(g)

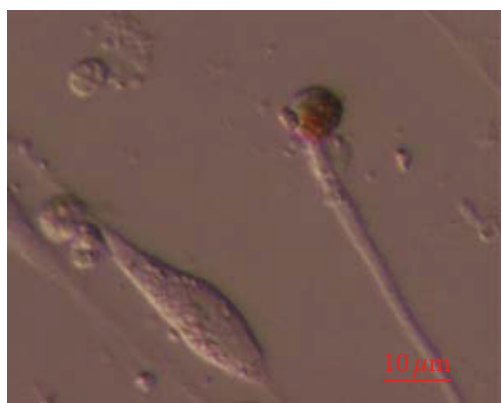

(b)

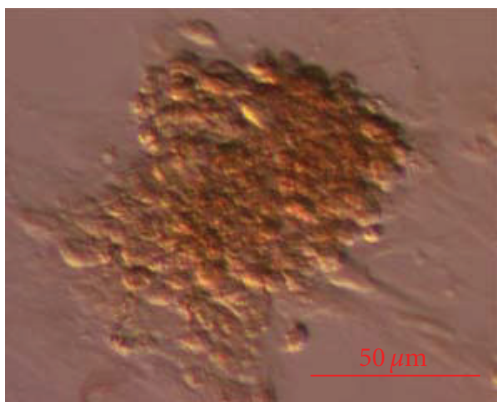

(d)

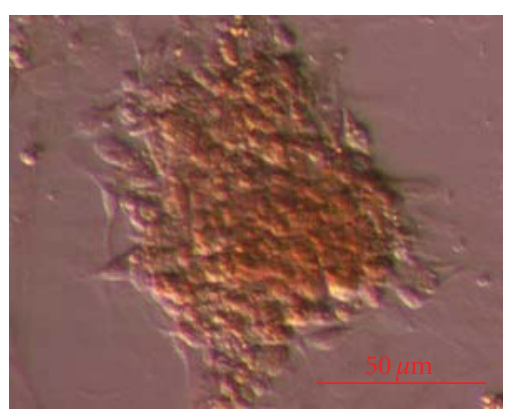

(f)

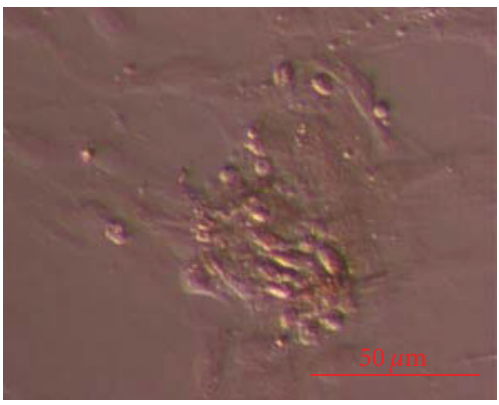

(h)

Figure 8: Differentiation of pancreatic-like cells. (a) Dithizone-positive (red) cell cluster. (b) Dithizone-positive (red) single cell. (c, d) Cpeptide-positive cell clusters. (e, f) Insulin-positive cell clusters. (g, h) Negative controls. (inverted microscope, Hoffman). Scale Bar: (a) $50 \mu \mathrm{m}$, (b) $10 \mu \mathrm{m},(\mathrm{a}-\mathrm{h}) 50 \mu \mathrm{m}$.

for neuronal differentiation, development of neuronal-like cells was found. Neuronal-like cells were appearing as single cells, or they formed some kind of nets. Neuronal-like cells were positively stained on S-100 marker (Figures 7(a)-7(d)), whereas they did not stain on some other markers, such as NSE and NeuN (data not shown). This indicated the potential glia cell-like character of neuronal-like cells rather than the real neuronal character.

Additionally, when cell cultures were exposed to the media for pancreatic differentiation, the cell morphology was changed, and development of typical colonies was observed (Figure 8). Cell cultures (some colonies and single cells) were 


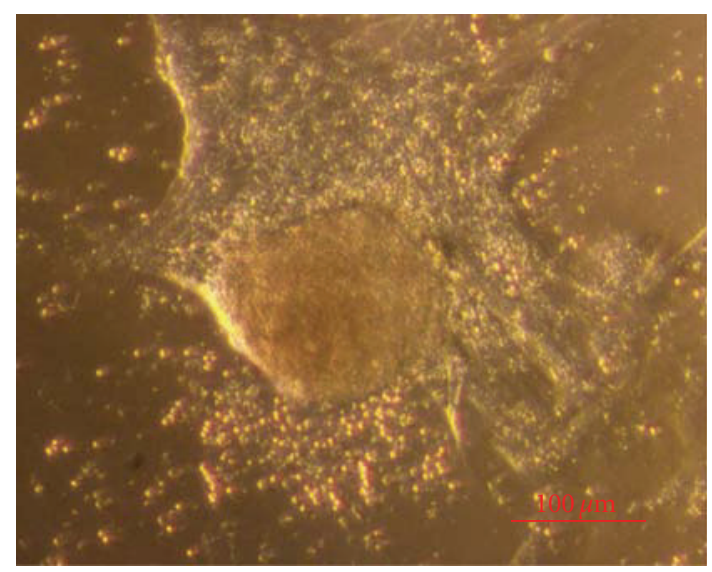

(a)

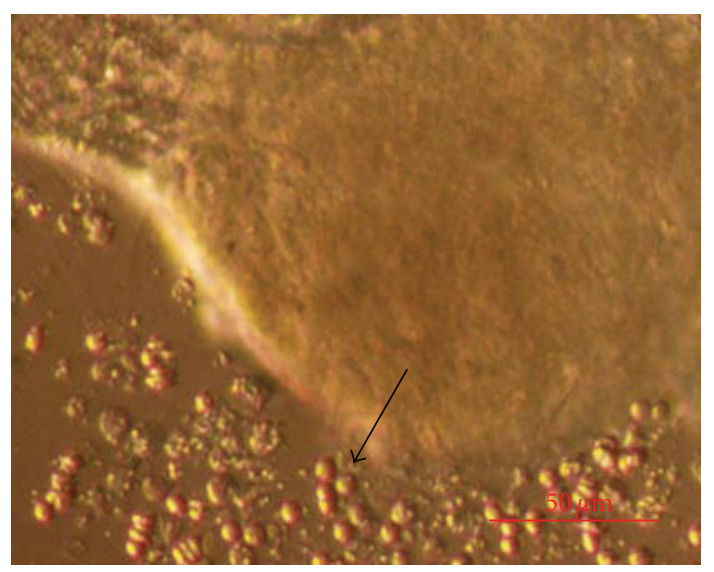

(b)

FIGURE 9: Testicular cell cluster (TSC1) cultured for 14 days in DMEM/F-12 culture medium with follicular fluid and expressing a variety of genes related to pluripotency and germ cells. (a) Morphology. (b) Small round and yellow cells with diameters of up to $5 \mu \mathrm{m}$ (arrow) in the close surrounding. (inverted microscope, Hoffman). Scale Bar: (a) $100 \mu \mathrm{m}$. (b) $50 \mu \mathrm{m}$.

positively stained on dithizone (Figures $8(\mathrm{a})$, and $8(\mathrm{~b})$ ), cpeptide (Figures $8(\mathrm{c})$, and $8(\mathrm{~d})$ ), and insulin (Figures $8(\mathrm{e})$, and $8(\mathrm{f}))$, as revealed by immunocytochemistry.

5.3. Gene Expressions of Cell Clusters. Four samples of 6 testicular cell clusters were isolated from one cell culture: TSC1one cluster cultured for 14 days in DMEM/F-12 medium with follicular fluid, TSC2-one cluster cultured for 14 days in hESC medium with follicular fluid, TSC3 - two clusters cultured for 140 days in DMEM/F-12 medium with follicular fluid, and TSC4-two clusters cultured for 140 days in DMEM/F-12 medium with follicular fluid. Gene expression in these samples was compared with control groups based on human embryonic stem cells-H1 line (150 and 200 cells) and human fibroblasts (150 and 200 cells). Cluster TSC1 (Figure 9(a)) strongly expressed a variety of genes related to pluripotency. In culture, small round cells with yellow colour and a diameter of up to $5 \mu \mathrm{m}$ appeared close to this cluster (Figure 9(b)). Also the other cell clusters (Figures 10(a)$10(\mathrm{e})$ ) expressed some of the genes characteristic of pluripotency, but to lower extent than TSC1 (Figure 10(f)). Gene expression in the putative testicular stem cells (TSCs) was comparable to that in the human embryonic stem cells (hESC), but was quite different from the expression in the human fibroblasts, as reflected by the heatmap (Figure 10(f)), corresponding dendrogram (Figure 11(a)), PCA clustering (Figure 11(b)), and univariate analysis of the genes summarized by descriptive statistics (Figure 12); TSCs clustered with the hESCs and in the PCA they have similar PC1 score; they differ, however, in the PC2 (Figure 11(b)). The fibroblasts were clearly different. Comparing genes' expression between putative TSCs and hESCs and using Bonferroni correction for multiple testing, we found significantly lower expression of DNMT3B in TSC's $(P=0.00026)$. Genes DAZL, NANOS, KLF4, DNMT1, STELLA, NANOG, STAT3, OCT4A, and GPR 125 were differentially expressed at $P<0.05$ but cannot be considered significant without validation because of the large number of genes compared (Figure 12(a)). On the other hand, fibroblasts showed quite different expression; in particular they did not express many of the genes related to pluripotency. Comparing with TSCs they underexpress OCT4A $(P=0.00187)$, NANOG $(P=0.00206)$, SOX-2 $(P=0.00145)$, and NANOS $(P=0.00247)$ (Figure 12(b)). Comparing with hESCs they underexpress OCT4A $(P=$ $0.00108)$, OCT4B $(P=0.00045)$, NANOG $(P=0.00151)$, SOX-2 $(P=0.00014), D N M T 3 B(P=0.00106)$, and CDH1 $(P=0.00066)$. One-way ANOVA confirmed that the variation in genes' expression among the groups TSCs, hESCs, and fibroblasts was larger than expected by chance for OCT4A $(P=0.00040), \operatorname{LIN28}(P=0.00170), \operatorname{GDF} 3(P=$ $0.00012)$, NANOG (0.00044), SOX-2 $(P=0.00044)$, TDGF1 $(P=0.00154)$, DNMT3B $(P=0.00011)$, TERT $(P=$ $6.068 E-5)$, NANOS $(P=0.00126)$, and CDH1 $(P=2 E-8)$. These results were consistent with the observations by flow cytometry and immunocytochemistry.

In the researched testicular biopsies differentiation of cell cultures into cells of all three germ layers (adipogenic cellsmesoderm, pancreatic-like cells-endoderm, and neuronallike cells-ectoderm) was found in spite of relatively low amount of processed testicular tissue. Additionally, there was some experimental evidence about the possible presence of putative mesenchymal and putative pluripotent stem cells forming clusters and their differentiation in vitro into adipose-like and neuronal-like cells, as induced by the follicular fluid addition. The population of putative stem cells found in this study seems to be comparable to the previously found population of putative stem cells from adult human testes expressing most of the mesenchymal stem cell markers (including CD105) and also some pluripotent stem cell markers (OCT4, SOX2, NANOG) and differentiating in vitro into adipogenic, osteogenic, and chondrogenic cells, as published by Gonzalez et al. [20]. Our study has shown that we are dealing with two different populations of stem cells in adult testes, mesenchymal and pluripotent, possibly. More advanced characterisation of putative stem cells from adult human testes is needed, respecting the nonclear distinction between 


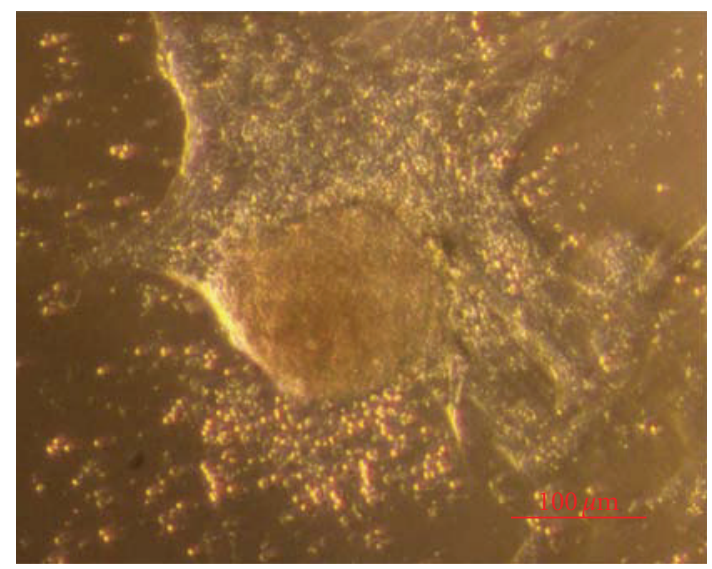

(a)

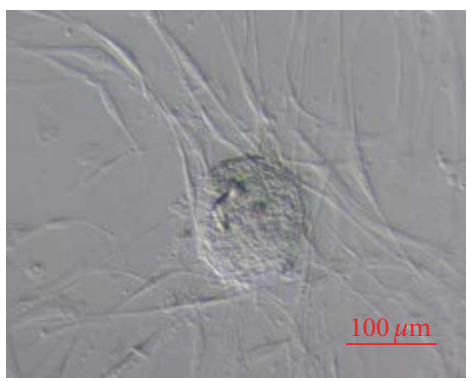

(c)

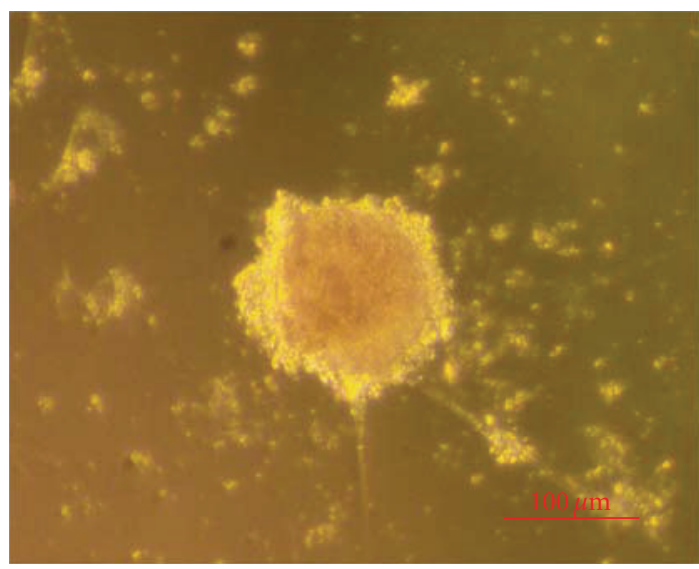

(b)

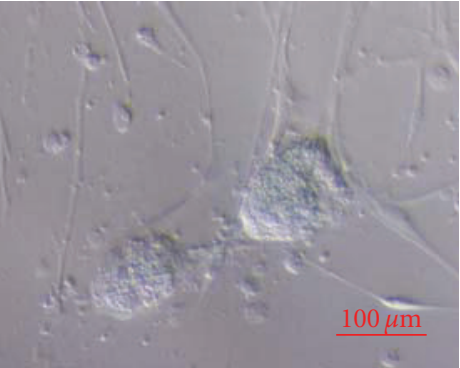

(d)

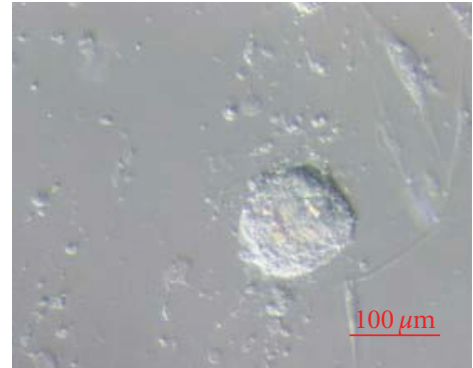

(e)
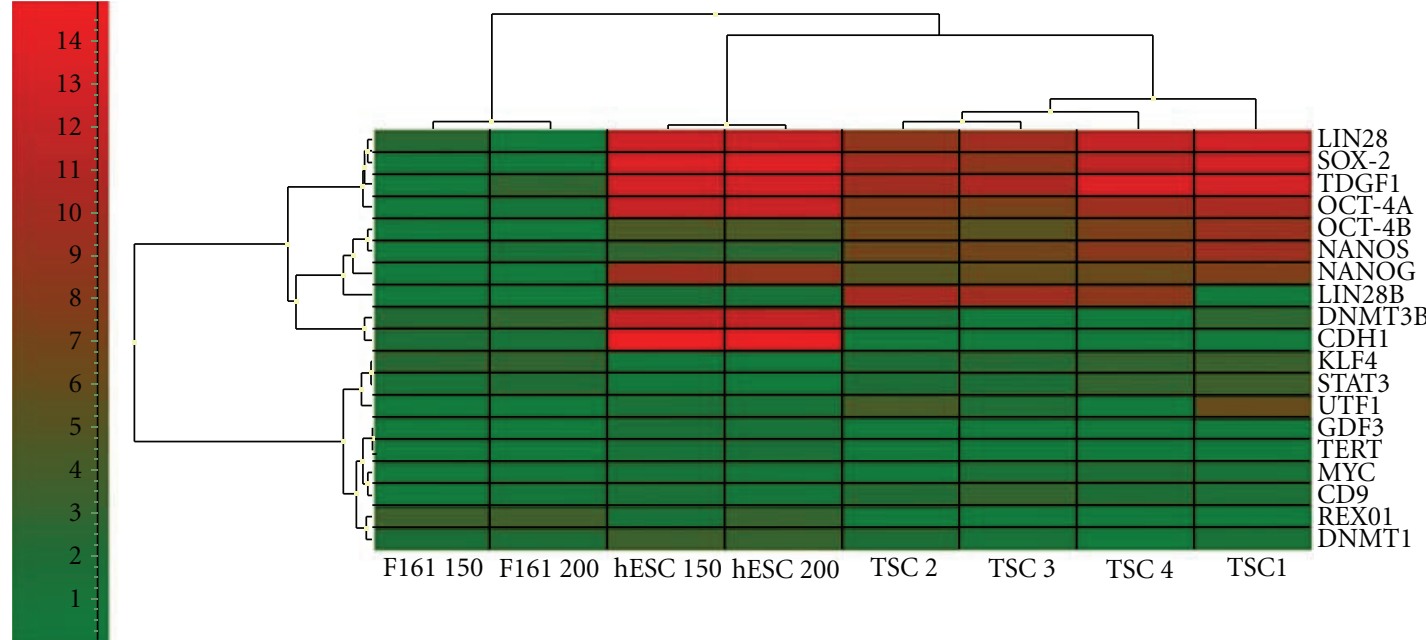

(f)

FIgURE 10: Testicular cell clusters and their gene expression analyses. (a) TSC1. (b) TSC2. (c) TSC3. (d, e) TSC4. (inverted microscope, Hoffman, with/without Autowhite). (f) Heatmap comparing genes' expressions in testicular cell clusters with human embryonic stem cells and fibroblasts. Scale Bar: (a-e) is $100 \mu \mathrm{m}$.

mesenchymal and embryonic-like pluripotent stem cells [3941].

The results of this study have shown that a relatively small amount of frozen-thawed testicular tissue without sperm and with an early germ cell maturation arrest expressed some level of stemness induced in vitro by heterologous follicular fluid added to the culture medium or by differentiation media and cultured in a testicular niche provided by the presence of other testicular cells after enzymatic degradation. This observation definitely needs to be further studied to solve the important clinical problem about the testicular tissue without sperm retrieved in the assisted reproduction programmes, possibly. Frozen-thawed or fresh testicular tissue of azoospermics without sperm is thrown away in daily medical practice, but could possibly be useful for different autologous cell therapies in the future. 


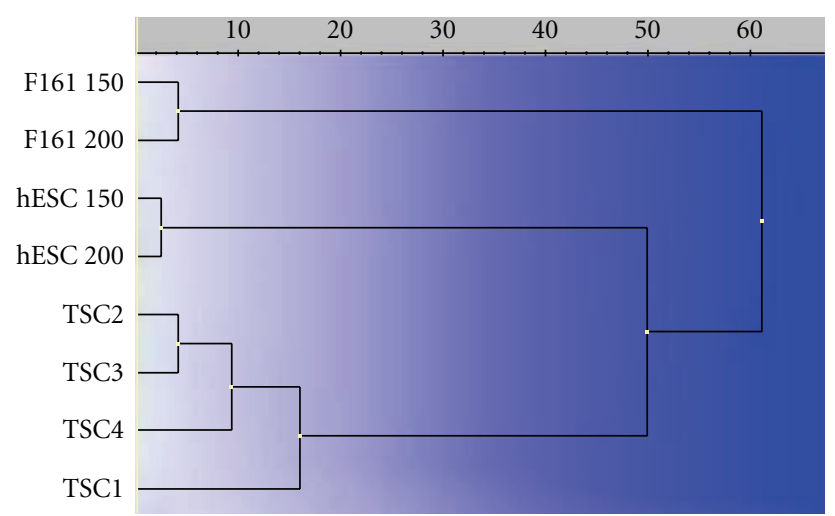

(a)

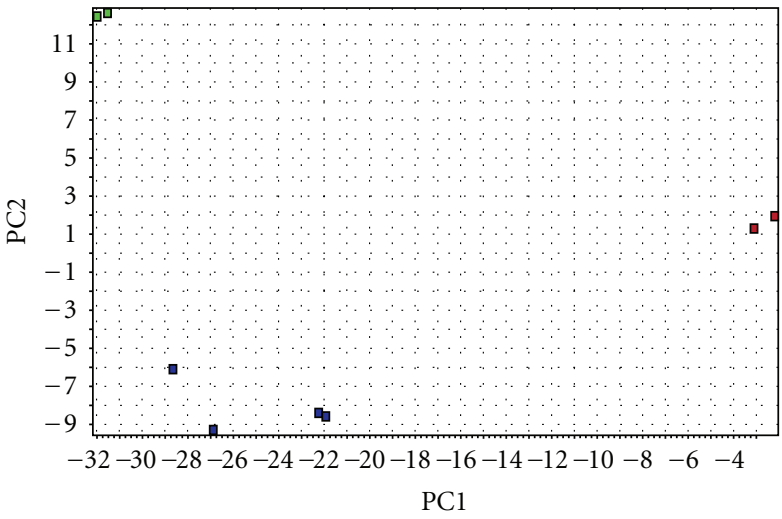

(b)

Figure 11: Testicular cell clusters and their gene expression analyses. (a) Dendrogram from hierarchical clustering. (b) Principal component analysis (green-hESCs, blue-testicular stem cells TSCs, red-fibroblasts).

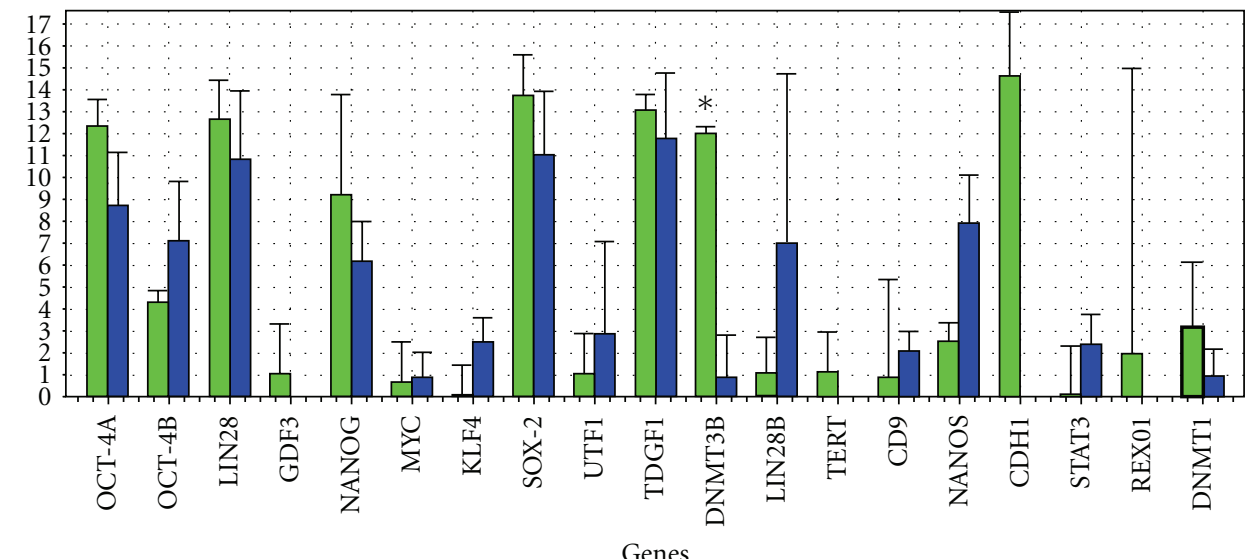

T hES

T TSC

(a)

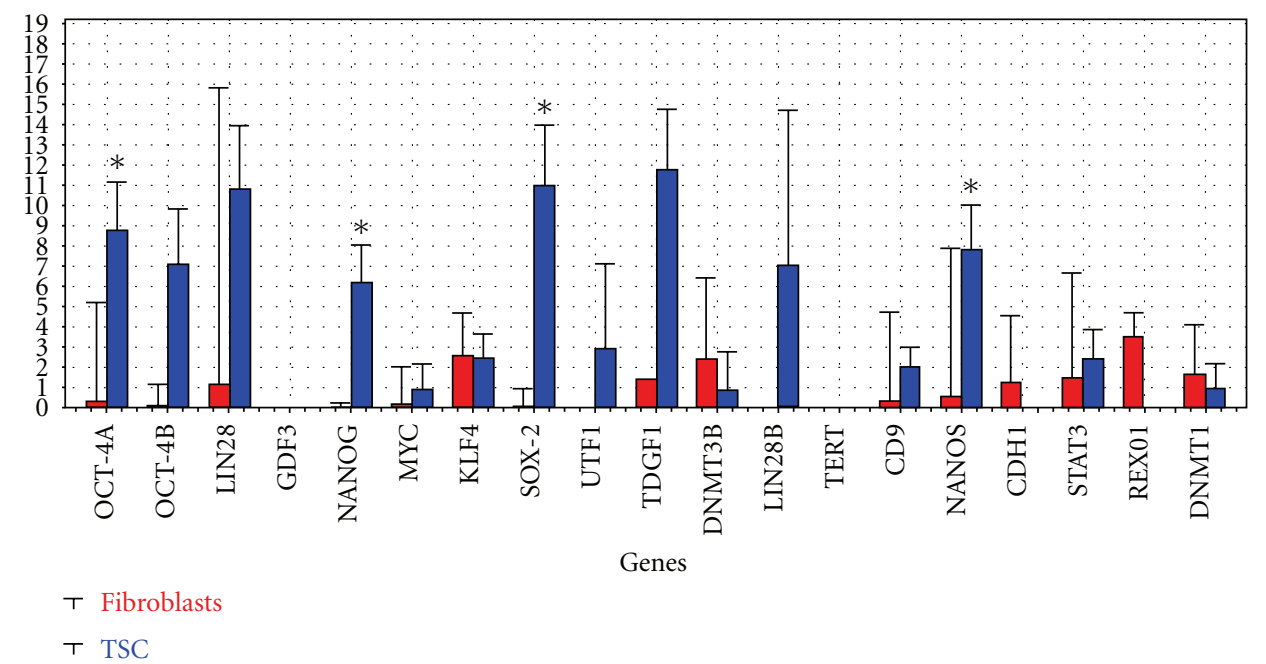

(b)

Figure 12: Descriptive statistics of genes' expressions. (a) Putative testicular stem cells (TSC1,2,3,4) compared to human embryonic stem cells hESC (150 and 200). (b) Putative testicular stem cells (TSC1,2,3,4) compared to human fibroblasts (150 and 100) *statistically significant difference based on $t$-Test with Bonferroni correction $(P=0.00270)$. 


\section{Acknowledgments}

The authors would like to thank pathologist Dr. Jasna Šinkovec and andrologist Dr. Branko Zorn, Assistant Professor, Department of Obstetrics and Gynaecology, University Medical Centre Ljubljana, for providing the patient's histological diagnosis and medical history, Mr. Lenart Girandon, B.S., Educell, d.o.o. for providing the Red Oil O and the verified protocol for staining of the adipose tissue-lipid droplets. This study was funded by the research grant of Dr. Irma Virant-Klun (Slovenian Research Agency ARRS).

\section{References}

[1] M. Kanatsu-Shinohara, N. Ogonuki, K. Inoue et al., "Longterm proliferation in culture and germline transmission of mouse male germline stem cells," Biology of Reproduction, vol. 69, no. 2, pp. 612-616, 2003.

[2] M. Kanatsu-Shinohara, K. Inoue, J. Lee et al., "Generation of pluripotent stem cells from neonatal mouse testis," Cell, vol. 119, no. 7, pp. 1001-1012, 2004.

[3] M. Kanatsu-Shinohara, M. Ikawa, M. Takehashi et al., "Production of knockout mice by random or targeted mutagenesis in spermatogonial stem cells," Proceedings of the National Academy of Sciences of the United States of America, vol. 103, no. 21, pp. 8018-8023, 2006.

[4] M. Kanatsu-Shinohara, K. Inoue, H. Miki et al., "Clonal origin of germ cell colonies after spermatogonial transplantation in mice," Biology of Reproduction, vol. 75, no. 1, pp. 68-74, 2006.

[5] K. Guan, K. Nayernia, L. S. Maier et al., "Pluripotency of spermatogonial stem cells from adult mouse testis," Nature, vol. 440, no. 7088, pp. 1199-1203, 2006.

[6] M. Seandel, D. James, S. V. Shmelkov et al., "Generation of functional multipotent adult stem cells from GPR $125^{+}$germline progenitors," Nature, vol. 449, no. 7160, pp. 346-350, 2007.

[7] F. Izadyar, F. Pau, J. Marh et al., "Generation of multipotent cell lines from a distinct population of male germ line stem cells," Reproduction, vol. 135, no. 6, pp. 771-784, 2008.

[8] Y. H. Huang, C. C. Chin, N. N. Ho et al., "Pluripotency of mouse spermatogonial stem cells maintained by IGF-1- Dependent pathway," FASEB Journal, vol. 23, no. 7, pp. 20762087, 2009.

[9] K. Ko, N. Tapia, G. Wu et al., "Induction of pluripotency in adult unipotent germline stem cells," Cell Stem Cell, vol. 5, no. 1, pp. 87-96, 2009.

[10] N. Golestaneh, E. Beauchamp, S. Fallen, M. Kokkinaki, A. Üren, and M. Dym, "Wnt signaling promotes proliferation and stemness regulation of spermatogonial stem/progenitor cells," Reproduction, vol. 138, no. 1, pp. 151-162, 2009.

[11] S. Conrad, M. Renninger, J. Hennenlotter et al., "Generation of pluripotent stem cells from adult human testis," Nature, vol. 456, no. 7220, pp. 344-349, 2008.

[12] N. Kossack, J. Meneses, S. Shefi et al., "Isolation and characterization of pluripotent human spermatogonial stem cellderived cells," Stem Cells, vol. 27, no. 1, pp. 138-149, 2009.

[13] H. Sadri-Ardekani, S. C. Mizrak, S. K. M. Van Daalen et al., "Propagation of human spermatogonial stem cells in vitro," Journal of the American Medical Association, vol. 302, no. 19, pp. 2127-2134, 2009.

[14] J. J. Lim, S. Y. Sung, H. J. Kim et al., "Long-term proliferation and characterization of human spermatogonial stem cells obtained from obstructive and non-obstructive azoospermia under exogenous feeder-free culture conditions," Cell Proliferation, vol. 43, no. 4, pp. 405-417, 2010.

[15] D. H. K. Lim and E. R. Maher, "Genomic imprinting syndromes and cancer," Advances in Genetics, vol. 70, no. 10, pp. 145-175, 2010.

[16] K. Le Blanc and O. Ringdén, "Immunomodulation by mesenchymal stem cells and clinical experience," Journal of Internal Medicine, vol. 262, no. 5, pp. 509-525, 2007.

[17] M. Kassem and B. M. Abdallah, "Human bone-marrow-derived mesenchymal stem cells: biological characteristics and potential role in therapy of degenerative diseases," Cell and Tissue Research, vol. 331, no. 1, pp. 157-163, 2008.

[18] R. S. N. Tewarie, A. Hurtado, R. H. Bartels, A. Grotenhuis, and M. Oudega, "Stem cell-based therapies for spinal cord injury," Journal of Spinal Cord Medicine, vol. 32, no. 2, pp. 105-114, 2009.

[19] D. J. Prockop, "Repair of tissues by adult stem/progenitor cells (MSCs): controversies, myths, and changing paradigms," Molecular Therapy, vol. 17, no. 6, pp. 939-946, 2009.

[20] R. Gonzalez, L. Griparic, V. Vargas et al., "A putative mesenchymal stem cells population isolated from adult human testes," Biochemical and Biophysical Research Communications, vol. 385, no. 4, pp. 570-575, 2009.

[21] J. Becerra, L. Santos-Ruiz, J. A. Andrades, and M. Marí-Beffa, "The stem cell niche should be a key issue for cell therapy in regenerative medicine," Stem Cell Reviews and Reports, vol. 7, no. 2, pp. 248-255, 2011.

[22] D. G. De Rooij, “The spermatogonial stem cell niche," Microscopy Research and Technique, vol. 72, no. 8, pp. 580-585, 2009.

[23] S. Jang, H. H. Cho, Y. B. Cho, J. S. Park, and H. S. Jeong, "Functional neural differentiation of human adipose tissue-derived stem cells using bFGF and forskolin," BMC Cell Biology, vol. 11 , article 25, 2010.

[24] N. Lumelsky, O. Blondel, P. Laeng, I. Velasco, R. Ravin, and R. McKay, "Differentiation of embryonic stem cells to insulinsecreting structures similar to pancreatic islets," Science, vol. 292, no. 5520, pp. 1389-1394, 2001.

[25] H. Segev, B. Fishman, A. Ziskind, M. Shulman, and J. Itskovitz-Eldor, "Differentiation of human embryonic stem cells into insulin-producing clusters," Stem Cells, vol. 22, no. 3, pp. 265-274, 2004.

[26] P. Blyszczuk, C. Asbrand, A. Rozzo et al., "Embryonic stem cells differentiate into insulin-producing cells without selection of nestin-expressing cells," International Journal of Developmental Biology, vol. 48, no. 10, pp. 1095-1104, 2004.

[27] A. Shiroi, M. Yoshikawa, H. Yokota et al., "Identification of insulin-producing cells derived from embryonic stem cells by zinc-chelating dithizone," Stem Cells, vol. 20, no. 4, pp. 284292, 2002.

[28] I. J. M. Duijkers, W. N. P. Willemsen, H. M. G. Hollanders, C. J. C. M. Hamilton, C. M. G. Thomas, and H. M. Vemer, "Follicular fluid hormone concentrations after ovarian stimulation using gonadotropin preparations with different FSH/ LH ratios. II. Comparison of hMG and recombinant FSH,' International Journal of Fertility and Women's Medicine, vol. 42, no. 6, pp. 431-435, 1997.

[29] A. Velazquez, A. Reyes, J. Chargoy, and A. Rosado, "Amino acid and protein concentrations of human follicular fluid," Fertility and Sterility, vol. 28, no. 1, pp. 96-100, 1977.

[30] E. V. Bokal, K. F. Tacer, M. Vrbnjak et al., "Follicular sterol composition in gonadotrophin stimulated women with polycystic ovarian syndrome," Molecular and Cellular Endocrinology, vol. 249, no. 1-2, pp. 92-98, 2006. 
[31] J. Smitz, H. M. Picton, P. Platteau et al., "Principal findings from a multicenter trial investigating the safety of follicularfluid meiosis-activating sterol for in vitro maturation of human cumulus-enclosed oocytes," Fertility and Sterility, vol. 87, no. 4, pp. 949-964, 2007.

[32] U. Ulug, E. Turan, S. B. Tosun, H. F. Erden, and M. Bahceci, "Comparison of preovulatory follicular concentrations of epidermal growth factor, insulin-like growth factor-I, and inhibins $\mathrm{A}$ and $\mathrm{B}$ in women undergoing assisted conception treatment with gonadotropin-releasing hormone (GnRH) agonists and GnRH antagonists," Fertility and Sterility, vol. 87, no. 4, pp. 995-998, 2007.

[33] A. Salmassi, S. Zorn, L. Mettler, K. Koch, W. Jonat, and A. G. Schmutzler, "Circulating concentration of stem cell factor in serum of stimulated IVF patients," Reproductive BioMedicine Online, vol. 22, no. 2, pp. 140-147, 2011.

[34] D. Bhartiya, S. Kasiviswanathan, S. K. Unni et al., "Newer insights into premeiotic development of germ cells in adult human testis using Oct-4 as a stem cell marker," Journal of Histochemistry and Cytochemistry, vol. 58, no. 12, pp. 1093-1106, 2010.

[35] I. Virant-Klun, P. Rožman, B. Cvjeticanin et al., "Parthenogenetic embryo-like structures in the human ovarian surface epithelium cell culture in postmenopausal women with no naturally present follicles and oocytes," Stem Cells and Development, vol. 18, no. 1, pp. 137-150, 2009.

[36] M. Kucia, R. Reca, F. R. Campbell et al., "A population of very small embryonic-like (VSEL) CXCR4 ${ }^{+}$SSEA- $1^{+}$Oct- $4^{+}$stem cells identified in adult bone marrow," Leukemia, vol. 20, no. 5, pp. 857-869, 2006.

[37] M. Kucia, M. Halasa, M. Wysoczynski et al., "Morphological and molecular characterization of novel population of CXCR $4^{+}$SSEA $-4^{+}$Oct- $4^{+}$very small embryonic-like cells purified from human cord blood-preliminary report," Leukemia, vol. 21, no. 2, pp. 297-303, 2007.

[38] E. K. Zuba-Surma, M. Kucia, J. Ratajczak, and M. Z. Ratajczak, "Small stem cells in adult tissues: very small embryonic-like stem cells stand up!," Cytometry Part A, vol. 75, no. 1, pp. 413, 2009.

[39] U. Riekstina, I. Cakstina, V. Parfejevs et al., "Embryonic stem cell marker expression pattern in human mesenchymal stem cells derived from bone marrow, adipose tissue, heart and dermis," Stem Cell Reviews and Reports, vol. 5, no. 4, pp. 378386, 2009.

[40] O. Trubiani, S. F. Zalzal, R. Paganelli et al., "Expression profile of the embryonic markers nanog, OCT-4, SSEA-1, SSEA-4, and Frizzled-9 receptor in human periodontal ligament mesenchymal stem cells," Journal of Cellular Physiology, vol. 225, no. 1, pp. 123-131, 2010.

[41] Y. Kuroda, M. Kitada, S. Wakao et al., "Unique multipotent cells in adult human mesenchymal cell populations," Proceedings of the National Academy of Sciences of the United States of America, vol. 107, no. 19, pp. 8639-8643, 2010. 

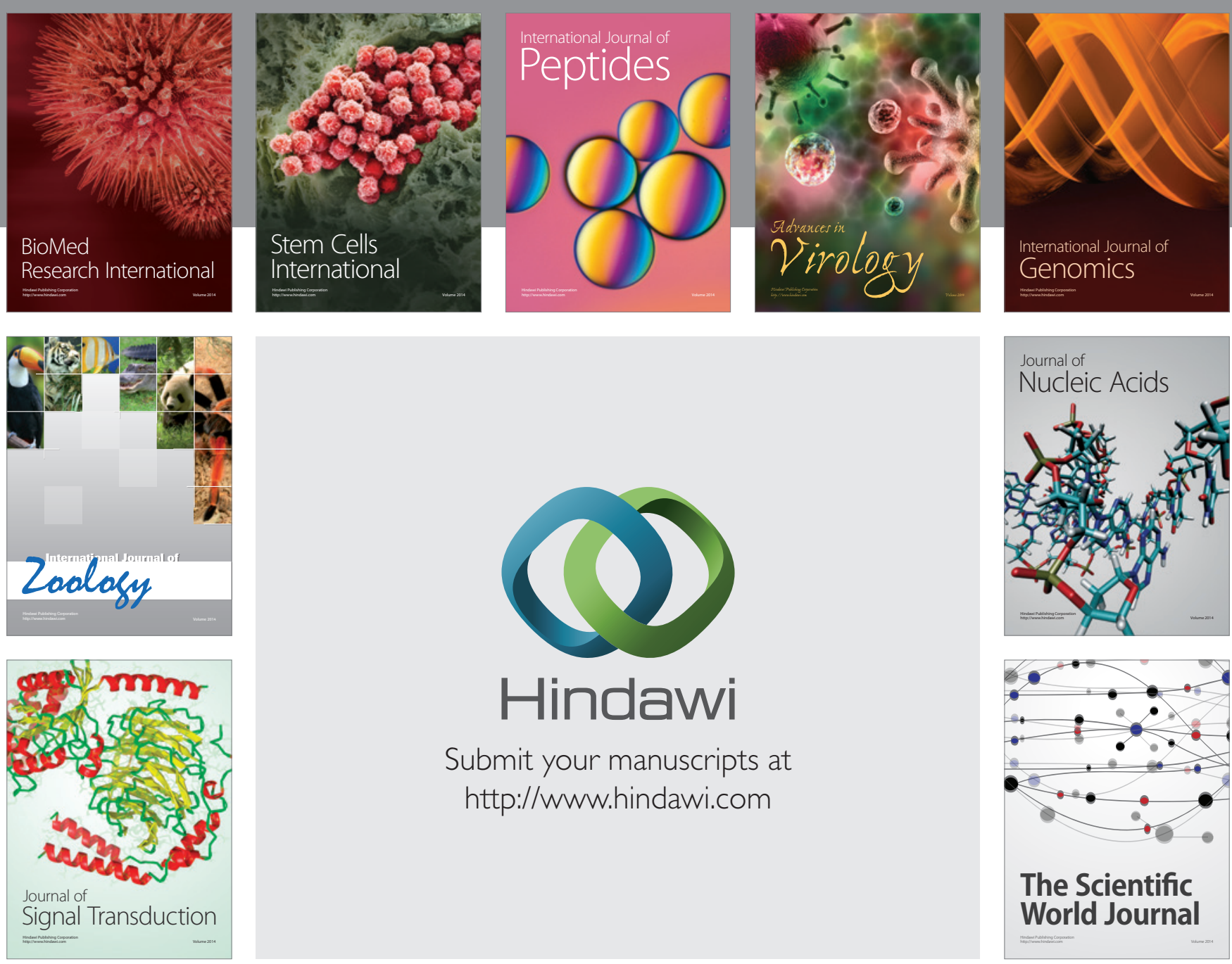

Submit your manuscripts at

http://www.hindawi.com
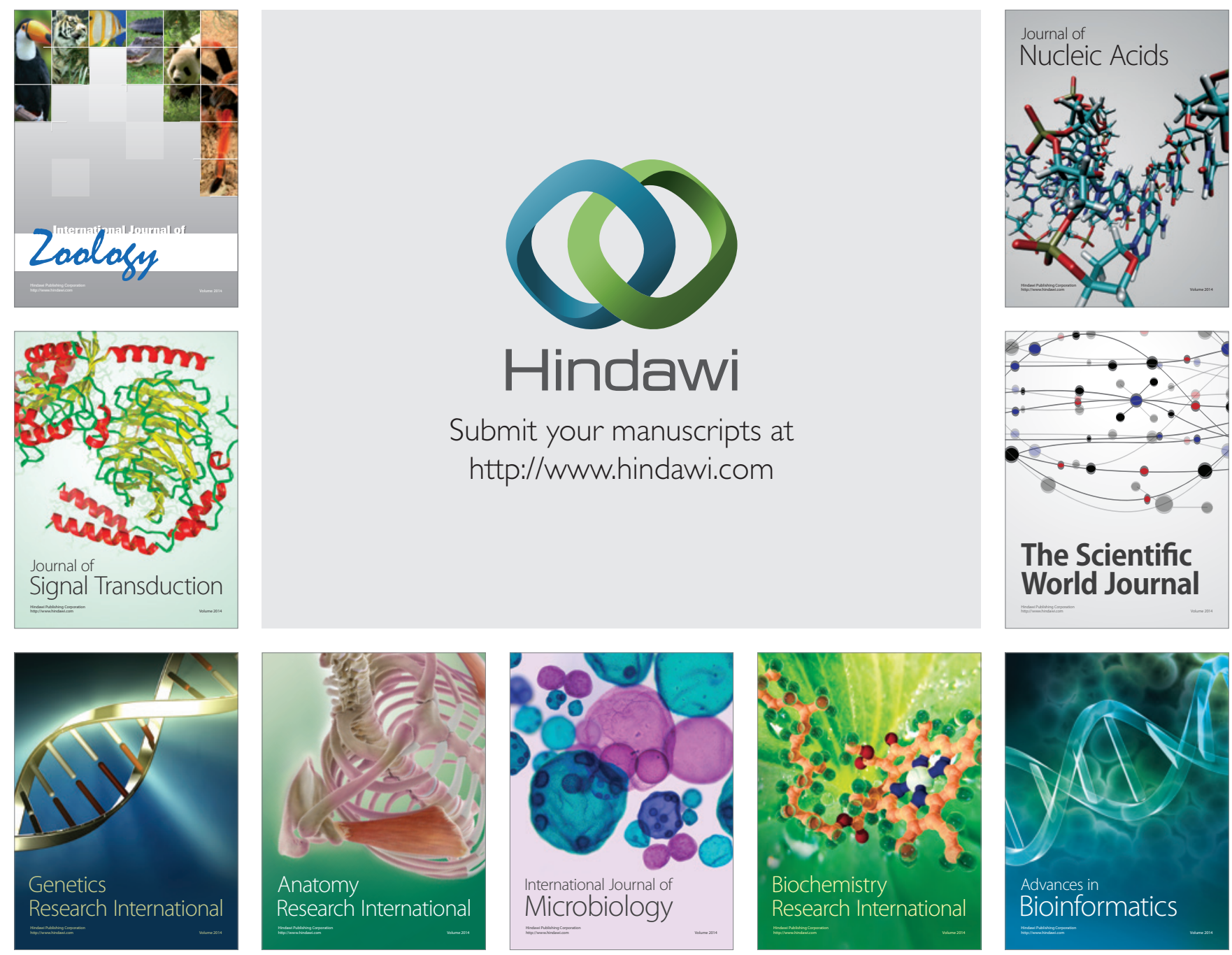

The Scientific World Journal
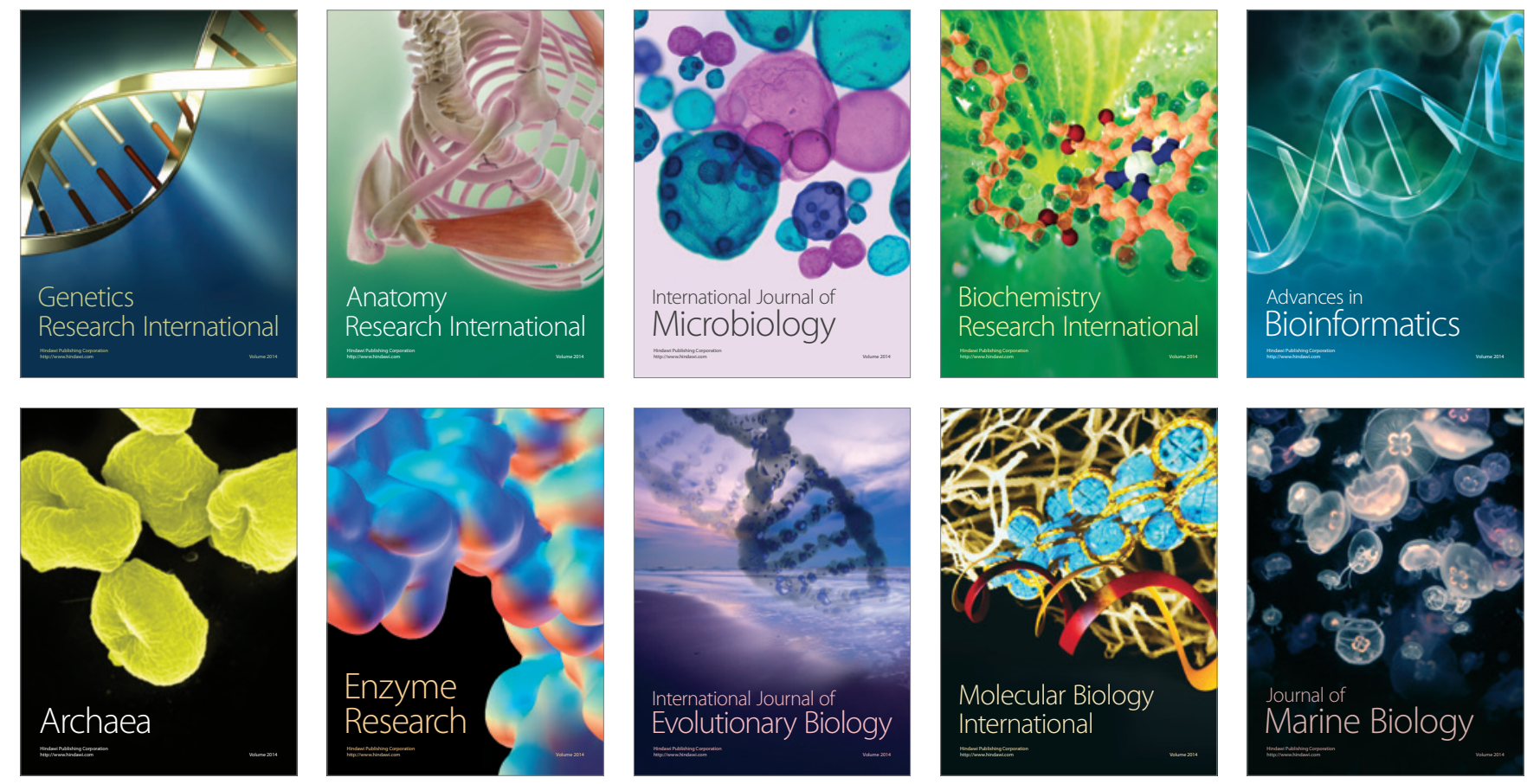